\title{
Lattice Boltzmann Simulation of Airflow and Mixed Convection in a General Ward of Hospital
}

\author{
Taasnim Ahmed Himika, Md. Farhad Hasan, and Md. Mamun Molla \\ Department of Mathematics \& Physics, North South University, Dhaka 1229, Bangladesh \\ Correspondence should be addressed to Md. Mamun Molla; mamun.molla@northsouth.edu
}

Received 16 January 2016; Accepted 11 April 2016

Academic Editor: M'hamed Souli

Copyright (C) 2016 Taasnim Ahmed Himika et al. This is an open access article distributed under the Creative Commons Attribution License, which permits unrestricted use, distribution, and reproduction in any medium, provided the original work is properly cited.

\begin{abstract}
In the present investigation the airflow and heat transfer for mixed convection have been simulated for a model general ward of hospital with six beds and partitions using the Lattice Boltzmann Method (LBM). Three different Reynolds numbers 100, 250, and 350 have been considered. Bounce-back condition has been applied at the wall. Results have been represented in three different case studies and the changes have been discussed in terms of streamlines and isotherms. Code validation has also been included before going through the simulation process and it shows good agreement with previously published papers when the comparison is made on average Nusselt number. Results show that the pattern of indoor airflow is varied in each and every case study due to the effect of mixed convection flow and placement of partition. In addition, the changes in average rate of heat transfer indicate that patients closer to inlet get the most air and feel better and if any patient does not need much air, he or she should be kept near the outlet to avoid temperature related complications.
\end{abstract}

\section{Introduction}

The study of mixed convection fluid flows has become an attention-grabber due to considerable practical interest in many engineering applications, such as nuclear reactors [1], crystal growth, solar collectors [2], and reservoirs and lakes [3]. Apart from these, mixed convection appears to be a concerning issue while designing modern ventilation system in high-rise buildings and health care centers. The main purpose of room air-ventilation system is to provide comfortable and good indoor air quality with minimum energy consumption so that the residents inside do not feel stuffy or uncomfortable. So, to design efficient ventilation system, necessary designing or simulation tools are required in order to accurately visualize the airflow pattern and know the appropriate positions of inlets and outlets in any complex geometry.

The combined effect of natural and forced convection in fluid flows has been analyzed by many researchers over decades. The fact behind their curiosity lies in the buoyancy effect that can be the dominant factor in determining heat transfer. Since experimental scale modeling is very expensive, researchers continued their study with the aid of traditional
Computational Fluid Dynamics (CFD) model simulation technique. But the main problem with this traditional method involves solving the Navier-Stokes (NS) equations that needs more CPU time and memory. Researchers found that the solution lies in the Lattice Boltzmann Model (LBM), an alternative Computational Fluid Dynamics (CFD) model that does the same job by solving discrete Boltzmann equation which is a faster process than solving the NS equations [4]. LBM has originated from Lattice Gas Automata (LGA) [5] which is used to simulate fluid dynamics by tracing the movement of single-particle distribution function considering the space, time, and particle velocities to be discrete.

The reasons behind LBM's popularity are as follows: because it has simple mathematical modeling of any complex system, the boundaries are treated in simple manner, it is a suitable model for parallel computation, and, apparently, it saves 30 percent of the total CPU time which would have been occupied by nonlinear Riemann problem in CFD [6]. LBM is also considered to be very easy and efficient method over finite volume, finite-difference, and finite element techniques. Many experiments and researches were performed to explore the effectiveness of LBM. Peng et al. [7] simplified thermal 
LBM to study incompressible thermal flows. Lee et al. [8] researched the incompressible lattice Bhatnagar-GrossKrook (BGK) model to simulate axisymmetric geometry. Sidik [9] calculated the temperature field and velocity field utilizing two different distribution functions for each field and developed an incompressible 2D and 3D thermohydrodynamics for the LBM. The main aim of Mondal and Li's [10] investigation was to observe the effect that volumetric radiation has on the natural convection in a square cavity containing an absorbing, emitting, and scattering medium. Szucki and Suchy [11] studied a method concerning local viscosity changes in single-relaxation time (SRT) LBM. Moreover, LBM was successful in various fluid dynamical problems including flows in porous media [12], magnetohydrodynamics [13], immiscible fluids [14], and turbulence [15]. LBM can also be applied to investigate indoor airflow. In 2002 Crouse et al. [16] were the first and probably the only ones to implement LBM in indoor convective airflow analysis.

An investigation was carried out by Zhang et al. [17] who studied the airflow inside an airliner ward performing experimental mathematics and numerical simulations. The ward was assumed to be half occupied with 28 seats and twin-aisle. The authors used the Reynolds averaged Navier-Stokes equations based on the RNG $k-\epsilon$ model to solve the air velocity, air temperature, and gas contaminant concentration and applied a Lagrangian technique to model the particle transport. The numerical results showed good agreement quantitatively with their experimental data. However, they confessed that it is very challenging and difficult to achieve a complete and accurate validation for the complex flow in a ward. Later, Zhang and Lin [18] used LBM to analyze indoor airflows. They worked on low Reynolds number indoor airflow fields in a model room building a partition and their computational results of LBM were found to be in agreement with the experimental data in terms of airflow velocities. They applied LBM in a relatively more complex environment, that is, a model ward with 10 beds. Although their works were solely on fluid flow, they did not consider any temperature equation.

Liu et al. [19], on the other hand, utilized CFD to examine a critical issue of hospital Operating Room (OR). They numerically simulated a horizontal airflow to control airborne particles inside a hospital OR. The investigation was performed on different horizontal airflow patterns and air quality inside an OR model of dimension $300 \mathrm{~cm} \times$ $296 \mathrm{~cm} \times 240 \mathrm{~cm}$. They realized the urgency of a proper ventilation system inside a hospital OR and, so, carried on some onsite tests and CFD simulations to estimate the effectiveness of latitudinal unidirectional airflow in order to bring down infectious airborne particles. The suggested ventilation supplying ultraclean air from a horizontal plane avoided obstacles, like medical lights from upstream flow, and also lateral flow perpendicular to the airflow of thermal plume around surgeons and patient can avoid opposing effect between the two airflows in downward airflow system. However, the application of airflow in horizontal direction had not been properly examined in their paper.

All the above examples verified the capability and effectiveness of LBM over traditional CFD, but the experiments were done either considering a natural fluid flow or forced fluid flow, whereas in reality the presence of both flows can be seen simultaneously. In purely natural convection flow, the only driving force is the density gradient, and for forced convection the force is inflow condition or pressure-gradient. Since there is temperature difference between all objects, living beings, and the environment, in the presence of a gravitational field temperature gradients tend to induce density gradients that ultimately drives the fluid flow. Watzinger and Johnson [20] took the first initiative to investigate heat transfer in a turbulent mixed convective water flow, both for opposing and supporting flow conditions. Later, Prasad and Koseff [21] investigated the combined natural and forced convection heat transfer in a deep lid-driven cavity flow. Hongtau Xu et al. [22] numerically studied double diffusive mixed convection around a heated cylinder in an enclosure and Al-Sanea et al. [23] analyzed the effect of input Reynolds number and room aspect ratio on turbulent flow and ceiling transfer coefficient for mixed convection using CFD method. Zhao et al. [24] used traditional CFD method to investigate three-dimensional (3D) nonlinear multiple steady fluid flows in a slot-ventilated enclosure. Khanafer and Chamkha [25] applied finite volume method to experiment with a fluidsaturated porous medium on mixed convection flow in a lid-driven enclosure. On the other hand, Kefayati et al. [26] applied LBM to simulate magnetohydrodynamic mixed convection in a lid-driven square cavity with linearly heated wall. As the present investigation is based on mixed convection inside a hospital ward having partition in the middle, the work of Lee and Awbi [27] is worth mentioning which is on the effect of room air quality with mixing ventilation due to internal partitioning, but their observation was only on statistical analysis using traditional CFD codes. They stated that to get better room air quality the partition positioned towards the exhaust zone having a larger height and gap underneath was beneficial.

The purpose of the present work is to focus on indoor airflow simulation by LBM in a hospital ward with six beds and partitions. The airflow inside the ward is considered to be mixed convection flow and different cases have been considered as well. The room temperature has been kept lower than patients' temperature as each patient on bed has been considered to release heat continuously in the proposed model. Before going through further simulation, code validation has been presented. This paper is organized in the following way: in Section 2, physical geometry of the problem has been discussed, followed by the mathematical formulation in Section 3. In Section 5, the results have been discussed in detail and then conclusion has been added to Section 7 .

\section{Physical Geometry}

The present investigation has been applied for the mixed convection in a general ward of hospital, as shown in Figure 1. In Figure 1(a), it is just a ward without any bed or partition; in Figure 1(b), a general ward with six model beds is shown and in Figure 1(c) that ward with six beds along with a partition is depicted. Here, $h$ is the height and $l=2 h$ is the horizontal length of each block and the height and width of the partition 


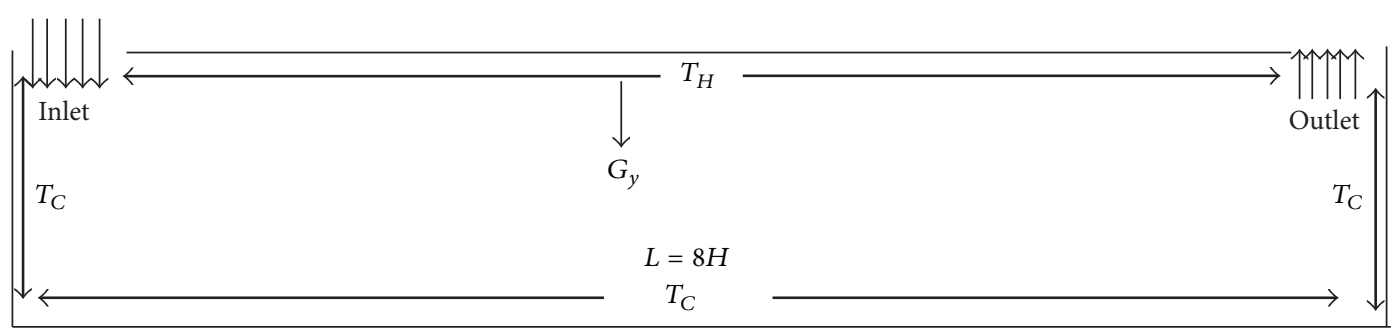

(a)

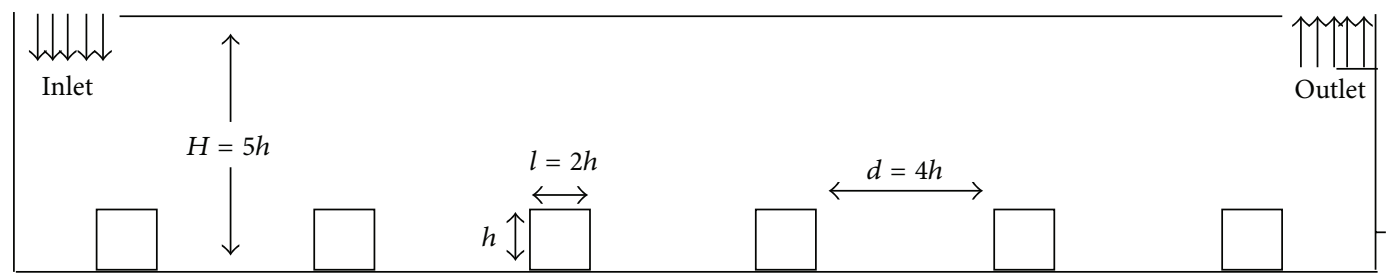

(b)

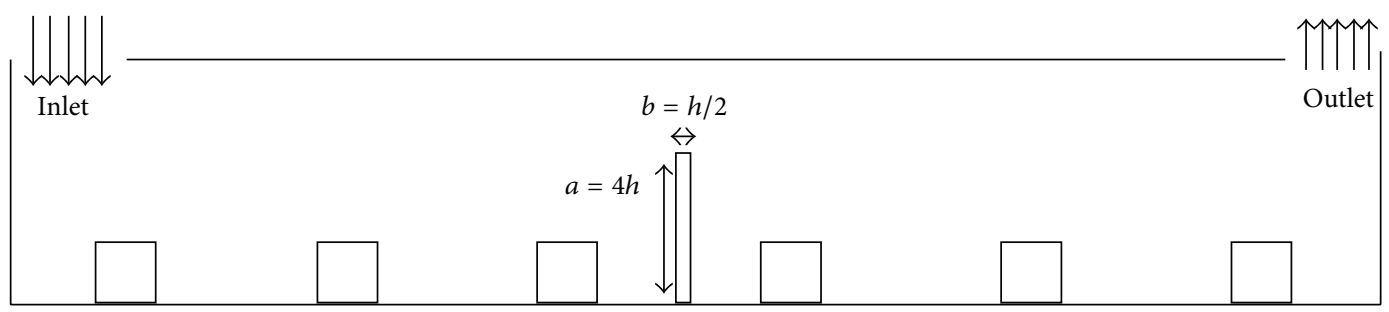

(c)

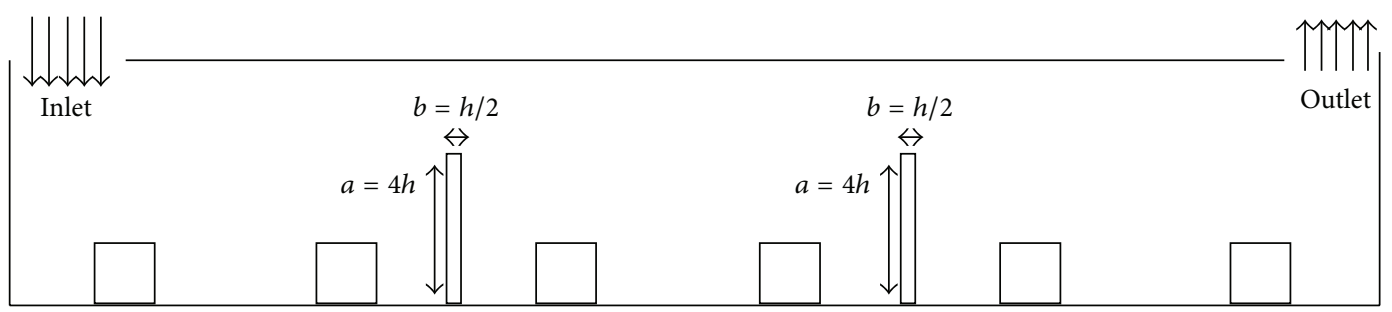

(d)

FIGURE 1: Schematic diagram of the geometry of hospital ward showing (a) principles applied building the model, (b) Case I without partition, (c) Case II with one partition, and (d) Case III with two partitions.

are $a=4 h$ and $b=h / 2$, respectively. The height of the ward is $H=5 h$ and $L=8 H$ is the length of the ward. The length of the inlet and outlet is $(h+b) / 2$.

\section{Mathematical Formulation}

The LBM was originated from Ludwig Boltzmann's kinetic theory of gases. The basic theory of this equation is that gases or fluids can be imagined as consisting of a large number of tiny particles moving with random motion. The exchange of momentum and energy is found through particle streaming and collision between particles. So, this process can be demonstrated by the Boltzmann transport equation [28, 29]:

$$
\frac{\partial f}{\partial t}+\bar{u} \cdot \bar{\nabla} f=\Omega\left(f, f^{\mathrm{eq}}\right)
$$

where $f^{\mathrm{eq}}$ is the equilibrium distribution function, respectively, $\bar{u}$ is the particle velocity, and $\Omega$ is the collision operator. Here, $f$ represents $f\left(\bar{x}, e_{i}, t\right)$ which is the probability to locate a particle at position $x$ with velocity vector $e_{i}$ at time $t$.

3.1. Lattice Boltzmann Method. The LBM simplifies Boltzmann's original idea of gas dynamics by reducing the number of particles and circumscribing them to the nodes of a lattice. For a two-dimensional model, a particle is preferred to stream in a possible of 9 directions, including the one staying at rest. For this type of modeling, the most popular one is D2Q9 model which has been considered in this work. This is the standard model for two-dimensional structure for both flow and temperature conditions. The velocities for these conditions are known as macroscopic velocities. 
The discretized Lattice Boltzmann (LB) equations for both flow and temperature field can be written as follows [29]:

$$
\begin{aligned}
f_{i} & \left(\bar{x}+\delta \bar{e}_{i}, t+\delta t\right)-f_{i}(\bar{x}, t) \\
& =-\frac{1}{\tau_{v}}\left[f_{i}(\bar{x}, t)-f_{i}^{(\mathrm{eq})}(\bar{x}, t)\right]+\delta t \cdot F_{i}, \\
g_{i} & \left(\bar{x}+\delta \bar{e}_{i}, t+\delta t\right)-g_{i}(\bar{x}, t) \\
& =-\frac{1}{\tau_{\alpha}}\left[g_{i}(\bar{x}, t)-g_{i}^{(\mathrm{eq})}(\bar{x}, t)\right] .
\end{aligned}
$$

Here, $\tau_{v}=3 v+0.5$ and $\tau_{\alpha}=3 \alpha+0.5$ are the single-relaxation times that control the rate of approach to equilibrium, $f_{i}(\bar{x}, t)$ and $g_{i}(\bar{x}, t)$ are the density distribution functions for velocity and temperature, respectively, along the direction $\bar{e}_{i}$ at $(\bar{x}, t), v$ is the kinematic viscosity, and $\alpha$ is the thermal diffusivity. The particle speed is $\bar{e}_{i}$ and $\rho$ is the density.

To calculate the equilibrium distribution functions for the velocity, $f_{i}^{\mathrm{eq}}(\bar{x}, t)$, and for the temperature, $g_{i}^{\mathrm{eq}}(\bar{x}, t)$, the general expressions have been considered [29-31]:

$$
\begin{aligned}
& f_{i}^{\mathrm{eq}}=w_{i} \rho\left[1+\frac{3\left(\bar{e}_{i} \cdot \bar{u}\right)}{c^{2}}+\frac{9\left(\bar{e}_{i} \cdot \bar{u}\right)^{2}}{2 c^{4}}-\frac{3(\bar{u} \cdot \bar{u})}{2 c^{2}}\right], \\
& g_{i}^{\mathrm{eq}}=w_{i} T\left[1+\frac{3\left(\bar{e}_{i} \cdot \bar{u}\right)}{c^{2}}+\frac{9\left(\bar{e}_{i} \cdot \bar{u}\right)^{2}}{2 c^{4}}-\frac{3(\bar{u} \cdot \bar{u})}{2 c^{2}}\right],
\end{aligned}
$$

where $\bar{u}=(u, v)$ is the fluid velocity and $c=\Delta x / \Delta t=1$ is the lattice speed. The weighting factors $w_{i}$ for D2Q9 are given as [29]

$$
w_{i}= \begin{cases}\frac{4}{9}, & i=0 \\ \frac{1}{9}, & i=1,2,3,4 \\ \frac{1}{36}, & i=5,6,7,8 .\end{cases}
$$

The macroscopic fluid density $\rho$ and velocity $\bar{u}$ are obtained from the moments of the distribution function as follows [28]:

$$
\begin{aligned}
& \rho(\bar{x}, t)=\sum_{i=0}^{8} f_{i}(\bar{x}, t), \\
& \bar{u}(\bar{x}, t)=\frac{1}{\rho} \sum_{i=0}^{8} \bar{e}_{i} f_{i}(\bar{x}, t)
\end{aligned}
$$

and the temperature $T$ is obtained as [32]

$$
T=\sum_{i=0}^{8} g_{i}(\bar{x}, t)
$$

3.2. Boundary Conditions. Boundary conditions (BCs) are very important part for both the stability and the accuracy of any kind of numerical solution. For LB modeling, the discrete distribution functions on the boundary need to be taken care of to reflect the macroscopic BCs of the fluid. In this work, at the wall, the bounce-back condition has been applied.

Bounce-back BCs are usually used to implement no-slip conditions on the boundary. By the bounce-back condition, it is meant that when a particle of a certain fluid for discrete distribution function reaches a boundary node, the particle will scatter back to the fluid along with its incoming direction. Bounce-back condition can be of various types but on-grid bounce-back condition has been used in this paper.

3.2.1. Boundary Condition for Velocity. Four possible directions in two-dimensional structure-east, west, north, and south-have been considered in the proposed model and noslip or bounce-back boundary condition is used at the walls, which has been shown in Figure 1 .

At east (right), west (left), and south (bottom) walls the bounce-back condition has been applied and the resulting relations are given below in order:

$$
\begin{aligned}
& f_{3}=f_{1}, \\
& f_{7}=f_{5}, \\
& f_{6}=f_{8}, \\
& f_{1}=f_{3}, \\
& f_{5}=f_{7}, \\
& f_{8}=f_{6}, \\
& f_{2}=f_{4}, \\
& f_{5}=f_{7}, \\
& f_{6}=f_{8} .
\end{aligned}
$$

On the other hand, at the north (top) wall, three different boundary conditions have been applied. At the inlet, Zou and He boundary conditions have been applied as shown in the following [33]:

$$
\begin{aligned}
\rho_{N} & =\frac{\left(f_{0}+f_{1}+f_{3}+2\left(f_{2}+f_{6}+f_{5}\right)\right)}{(1+U)}, \\
f_{4} & =f_{2}-\frac{2}{3} \rho_{N} U, \\
f_{8} & =f_{6}-\frac{1}{6} \rho_{N} U, \\
f_{7} & =f_{5}-\frac{1}{6} \rho_{N} U,
\end{aligned}
$$

where $U$ is the bulk velocity based on the Reynolds number $\operatorname{Re} \stackrel{\text { def }}{=} U H / \nu$. At the outlet the following boundary conditions are used:

$$
\begin{aligned}
& f_{4, N}=f_{4, N-1}, \\
& f_{8, N}=f_{8, N-1}, \\
& f_{7, N}=f_{7, N-1}
\end{aligned}
$$


and bounce-back condition is used for the rest of the top walls. At the top surface and at each side of a block and partition, the following bounce-back conditions have been used:

Top surface:

$$
\begin{aligned}
& f_{2, x_{i}}=f_{4, x_{i}}, \\
& f_{5, x_{i}}=f_{7, x_{i}}, \\
& f_{6, x_{i}}=f_{8, x_{i}} .
\end{aligned}
$$

Left side:

$$
\begin{aligned}
& f_{1, x_{i}}=f_{3, x_{i}}, \\
& f_{5, x_{i}}=f_{7, x_{i}}, \\
& f_{8, x_{i}}=f_{6, x_{i}} .
\end{aligned}
$$

Right side:

$$
\begin{aligned}
& f_{3, x_{i}}=f_{1, x_{i}}, \\
& f_{6, x_{i}}=f_{8, x_{i}}, \\
& f_{7, x_{i}}=f_{5, x_{i}} .
\end{aligned}
$$

3.2.2. Boundary Condition for Temperature. Cold and hot temperature conditions are applied at the walls (see Figure 1).

At east (right) wall the cold temperature condition is $g_{3}=$ $-g_{1}, g_{7}=-g_{5}$, and $g_{6}=-g_{8}$.

At west (left) wall the cold temperature condition is $g_{1}=$ $-g_{3}, g_{5}=-g_{7}$, and $g_{8}=-g_{6}$.

At south (bottom) wall the cold temperature condition is $g_{2}=-g_{4}, g_{5}=-g_{7}$, and $g_{6}=-g_{8}$.

At the north (top) wall in the outlet a zero gradient boundary condition is applied as follows:

$$
\begin{aligned}
& g_{4, N}=g_{4, N-1}, \\
& g_{8, N}=g_{6, N-1}, \\
& g_{7, N}=g_{5, N-1} .
\end{aligned}
$$

And the rest of the top wall is kept cold by using the conditions $g_{4}=-g_{2}, g_{8}=-g_{6}$, and $g_{7}=-g_{5}$.

At the top surface of each block the hot temperature condition is used as follows:

$$
\begin{aligned}
& g_{2, y_{2}}=T_{w}\left(w_{2}+w_{4}\right)-g_{4, y_{2}}, \\
& g_{5, y_{2}}=T_{w}\left(w_{5}+w_{7}\right)-g_{7, y_{2}}, \\
& g_{6, y_{2}}=T_{w}\left(w_{6}+w_{8}\right)-g_{8, y_{2}},
\end{aligned}
$$

where $y_{2}$ indicates the top surface of the blocks and $T_{w}$ is the wall temperature.
3.3. Nondimensional Number and Mixed Convection Parameter. The important nondimensional number Grashof $(\mathrm{Gr})$ and Prandtl (Pr) numbers are defined as [32]

$$
\begin{aligned}
& \mathrm{Gr}=\frac{\beta G_{y} H^{3}\left(T_{H}-T_{C}\right)}{v^{2}}, \\
& \operatorname{Pr}=\frac{\nu}{\alpha} .
\end{aligned}
$$

In the mixed convection the Richardson number, $\mathrm{Ri} \stackrel{\text { def }}{=}$ $\mathrm{Gr} / \mathrm{Re}^{2}$, controls the flow phenomena. In this simulation the force term is defined as follows [34]:

$$
F=3 w_{i} \operatorname{Ri}\left(T-T_{m}\right) e_{y},
$$

where $T_{m}=\left(T_{H}+T_{C}\right) / 2$ is the mean temperature. In this paper the fluid velocity $\bar{u}$ is nondimensionalized by the constant inlet velocity $U$ and the nondimensional temperature is $\theta=\left(T-T_{c}\right) /\left(T_{w}-T_{c}\right)$.

In the present work, the Mach number $(\mathrm{Ma})$ for $\mathrm{Re}=100$ is 0.05 , for $\operatorname{Re}=250$ is 0.02 , and for $R e=350$ is 0.014 . All these values are less than 0.3 which satisfy the condition of incompressible fluid flow [32]. In buoyant flow, Mach number and thermal diffusivity $(\alpha)$ can be defined by the following equations after fixing the values of viscosity, Prandtl number, and Reynolds number:

$$
\begin{aligned}
\mathrm{Ma} & =\frac{\nu \sqrt{\mathrm{G}} \mathrm{r}}{N c}, \\
\alpha & =\frac{\nu}{\operatorname{Pr}} .
\end{aligned}
$$

\section{Convergence Criteria}

Standard LBM, being explicit time-marching in nature, requires a long time to attain steady state convergence. However, convergence of solution is one of the highlights of the procedure of recovering the Navier-Stokes equations from LBM. In this single-relaxation-time LBM, the iterative procedure is terminated when the velocity and temperature field satisfy the following convergence criteria:

$$
\frac{\sum\left|\phi^{(n+1)}-\phi^{(n)}\right|}{\sum\left|\phi^{(n+1)}\right|}<10^{-9},
$$

where $\phi$ is the velocity $\bar{u}$ or temperature $T$ and $n$ is the iteration index and the sum is over the whole domain.

\section{Results and Discussions}

This section has been divided into four subsections. At first, code validation has been performed for different values of Re and has been compared in tabular format. In the consequent three subsections, three case studies have been considered inside the hospital ward. In all three cases, one inlet, one outlet, and six beds have been considered. Simulations have been carried out by placing one partition and later two partitions in the room while observing the indoor airflow 
TABLE 1: Comparison of average Nusselt numbers of present work with other investigations for $\mathrm{Gr}=100$ and $\mathrm{Pr}=0.71$.

\begin{tabular}{lccccccccc}
\hline $\operatorname{Re}$ & $\mathrm{Ri}$ & Present & {$[35]$} & {$[25]$} & {$[36]$} & {$[37]$} & {$[38]$} & {$[39]$} & {$[26]$} \\
\hline 100 & 0.01 & 1.917965 & 1.94 & 2.01 & 2.02 & 1.985 & 2.10 & 2.03116 & 2.09 \\
400 & 0.00062 & 3.789101 & 3.84 & 3.91 & 4.01 & 3.8785 & 3.85 & 4.0246 & 4.08082 \\
1000 & 0.0001 & 6.339137 & 6.33 & 6.33 & 6.42 & 6.345 & 6.33 & 6.48423 & 6.54687 \\
\hline
\end{tabular}

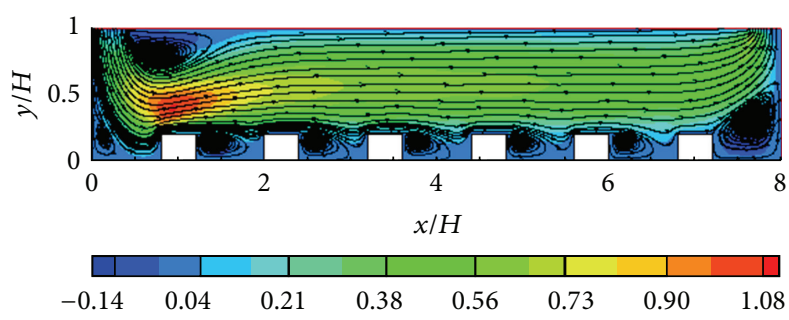

(a)

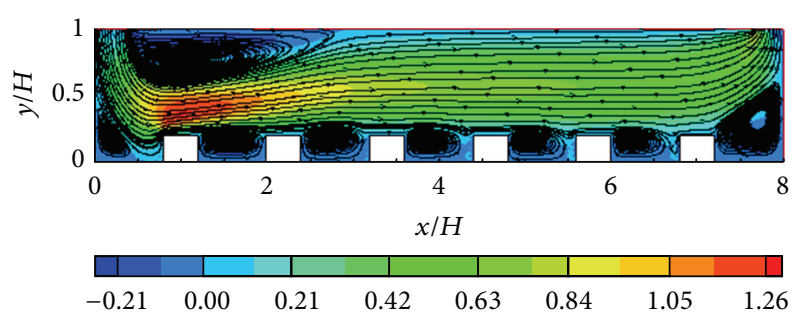

(b)

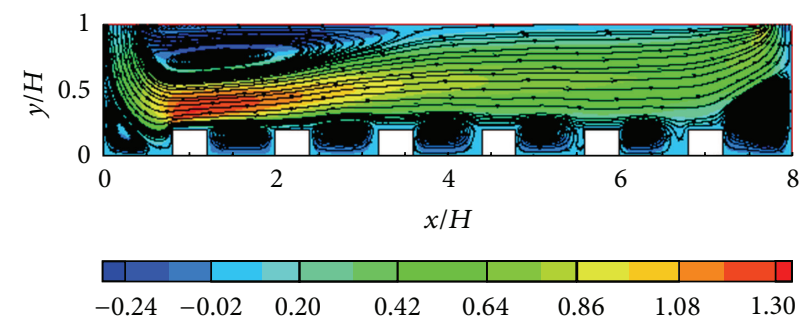

(c)

Figure 2: Streamline patterns of Case I for (a) $\operatorname{Re}=100$, (b) $\operatorname{Re}=250$, and (c) $\operatorname{Re}=350$.

pattern and the field of temperature in the three situations. This section is ended with the discussion and comparison of the average rate of change of heat transfers achieved for each case study. In these cases, $\operatorname{Re}=100,250$, and 350, $\operatorname{Pr}=0.71$, and $\mathrm{Ri}=1$ have been kept for all simulations except the code validation case. Different values of $\tau_{v}$ generated for different $\mathrm{Re}$ are as follows: for $\mathrm{Re}=100$, it is 0.575 , for $\mathrm{Re}=250$, it is 0.530 , and for $\operatorname{Re}=350$, it is 0.521 . Likewise, different values of $\tau_{\alpha}$ are as follows: for $\operatorname{Re}=350$, it is 0.53 , for $\operatorname{Re}=250$, it is 0.542 , and for $\operatorname{Re}=100$, it is 0.605 .

5.1. Code Validation. For code validation process, one test case is the mixed convection in a lid-driven square cavity flow for $\operatorname{Re}=100,400$, and 100 and $\mathrm{Gr}=100$ has been considered. The present results in terms of the average Nusselt number have been compared quantitatively with the available results published in different articles that are demonstrated in Table 1 . The comparison reveals a very good agreement. The results were compared with the works of Iwatsu et al. [35], Tiwari and Das [38], Kefayati et al. [26], Khanafer et al. [36], Abdelkhalek [37], Khanafer and Chamkha [25], and Waheed [39].

5.2. Case Study I: Six Beds without Partition in the Ward. In the first case study, six beds without partition have been considered. Each bed is of the same dimension. However, beds are represented as blocks in Figure 1. For the whole computational domain a lattice size of $(400 \times 50) \sim$ $(x \times y)$ has been taken in all simulations. Each block of
$(20 \times 10) \sim(x \times y)$ lattice size is used in the ward. The beds are uniformly distributed in one row. Inlet and outlet have been placed vertically on the ceiling on the left and right corners, respectively. The width of both the inlet and the outlet has been kept from 0 to 15 lattices and from 385 to 400 lattices, respectively.

Figures 2(a)-2(c) show the streamlines appended on $u / U$ velocity contour of the airflow that enters the ward through the inlet and flows out through the outlet for $\mathrm{Re}=100,250$, and 350, respectively. In case of $\mathrm{Re}=100$, small recirculations are seen between the blocks and also near the walls in the east and west sides of the ward due to bounce-back condition. A comparatively large recirculation is formed in immediate right to the inlet that is near the top wall. For increasing Re the length of the recirculation zones increases. As shown in Figure 2, the highest value of $u / U$ is 1.08 and the lowest value is -0.14 for $\mathrm{Re}=100$. In case of $\mathrm{Re}=250$ and 350 , the maximum values increase to 1.26 and 1.30 , respectively. As Re increases, the inertia force of air increases which makes it easier to flow around in the ward and, hence, more heat will be transferred out through the outlet.

Figure 3 represents the isotherms of the room. As can be seen from the simulation result, only the top surface of each block is kept heated while the gaps between the blocks are cold. The heated portion of the blocks represents patients on beds who are releasing heat continuously.

Different velocity patterns have been shown in Figures $4(\mathrm{a})-4(\mathrm{n})$ demonstrating the $u / U$ velocity profiles at different positions of $x / H$ for the three different Re. This figure 


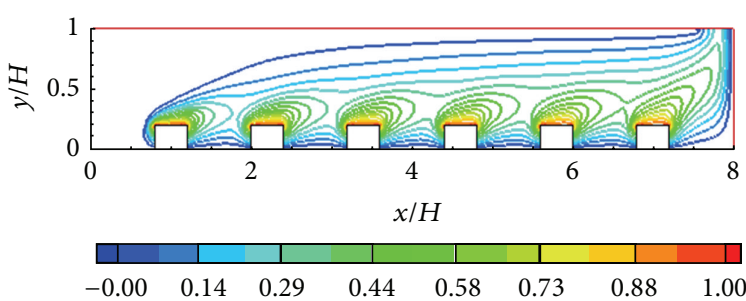

(a)

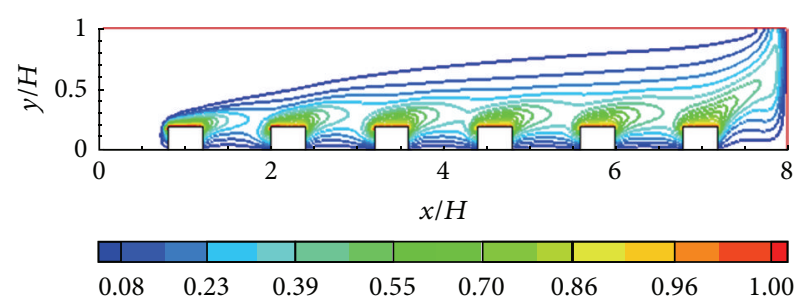

(b)

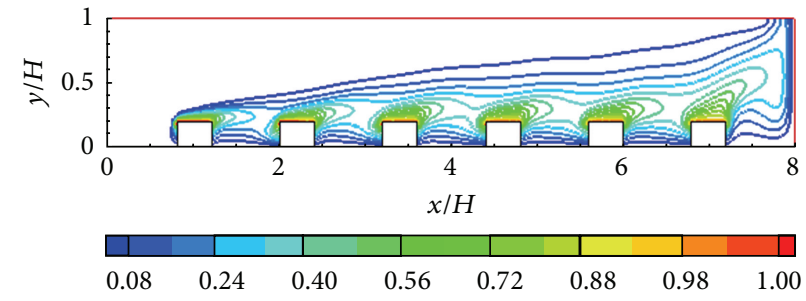

(c)

FIGURE 3: Isotherms of Case I for (a) $\operatorname{Re}=100$, (b) $\operatorname{Re}=250$, and (c) $\operatorname{Re}=350$

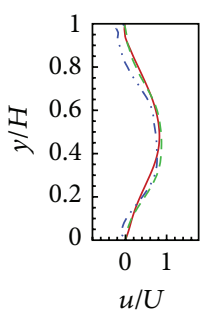

$-\operatorname{Re}=100$
$--\operatorname{Re}=250$
$-\cdots \operatorname{Re}=350$

(a)

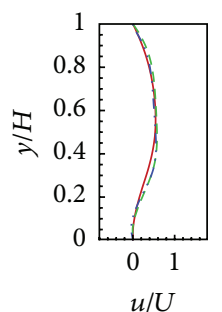

$-\operatorname{Re}=100$

$---\operatorname{Re}=250$

$-\cdots-\operatorname{Re}=350$

(h)

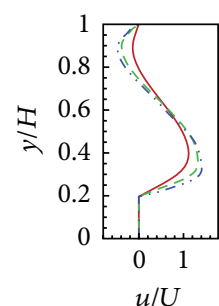

$-\operatorname{Re}=100$

$---\operatorname{Re}=250$

$-\cdots-\operatorname{Re}=350$

(b)

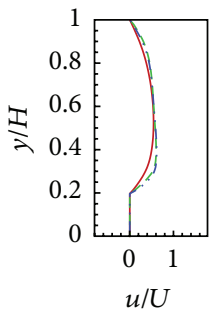

$\begin{aligned}- & \operatorname{Re}=100 \\ --- & \operatorname{Re}=250 \\ -\cdots- & \operatorname{Re}=350\end{aligned}$

(i)
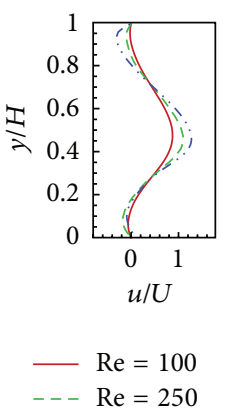

$\operatorname{Re}=3$

(c)

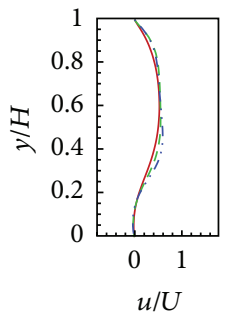
$-\operatorname{Re}=100$
$---\operatorname{Re}=250$
-..- $\mathrm{Re}=350$

(j)
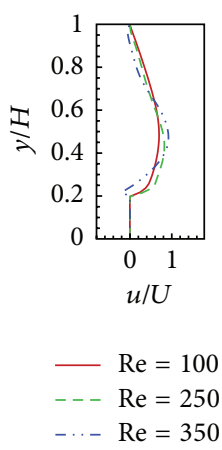

(d)

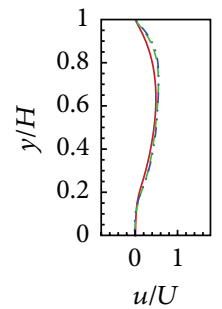

$\begin{aligned}- & \operatorname{Re}=100 \\ --- & \operatorname{Re}=250 \\ -\cdots- & \operatorname{Re}=350\end{aligned}$

(k)
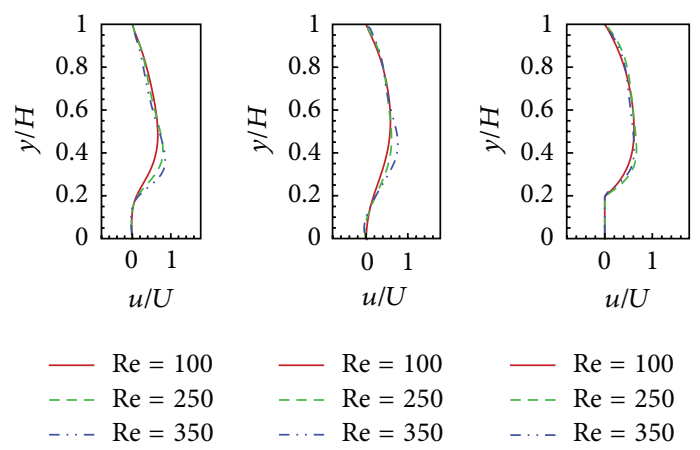

(e)

$$
\begin{aligned}
& -\operatorname{Re}=100 \\
& ---\operatorname{Re}=250 \\
& \text { - - }-\operatorname{Re}=350
\end{aligned}
$$

(f)
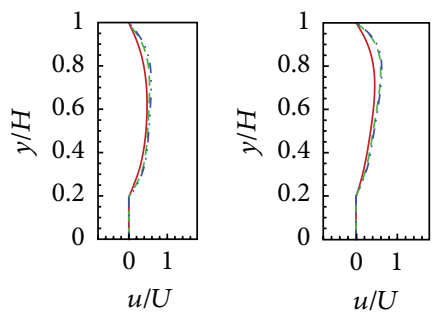

$\begin{aligned}- & \operatorname{Re}=100 \\ ---\operatorname{Re} & =250 \\ -\cdots- & \operatorname{Re}=350\end{aligned}$

(1) $\begin{aligned}- & \operatorname{Re}=100 \\ --- & \operatorname{Re}=250 \\ -\cdots- & \operatorname{Re}=350\end{aligned}$

(m)

$$
\begin{aligned}
& -\operatorname{Re}=100 \\
& --\operatorname{Re}=250 \\
& -\cdots-\operatorname{Re}=350
\end{aligned}
$$

(g)

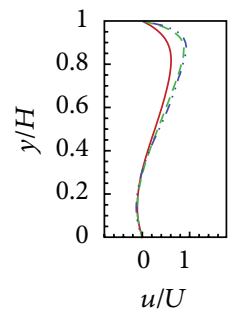

$$
\begin{aligned}
& -\operatorname{Re}=100 \\
& ---\operatorname{Re}=250 \\
& -\cdots-\operatorname{Re}=350
\end{aligned}
$$

(n)

Figure 4: $u / U$ velocity profiles in Case I for the different Re at different positions of horizontal locations (a) $x / H=0.5,(\mathrm{~b}) x / H=1,(\mathrm{c})$ $x / H=1.5$, (d) $x / H=2$, (e) $x / H=3$, (f) $x / H=3.5$, (g) $x / H=4$, (h) $x / H=4.5$, (i) $x / H=5$, (j) $x / H=5.5$, (k) $x / H=6$, (l) $x / H=6.5$, (m) $x / H=7$, and (n) $x / H=7.5$.

outlines the speed at which the air is flowing inside the ward. Due to the recirculation near the inlet, the velocity profiles are also seen to increase resulting in a bent-shaped plot in Figures 4 (b) and 4(c). After $x / H=3.5$ onwards the graphs are almost the same as there the flow characteristics are almost similar, except for Figure 4(n) which is slightly bent at the top forming because at this point the air is preparing to go through the outlet.

5.3. Case Study II: Six Beds with One Partition. In this investigation, the previous model has been updated by adding a partition in the middle of the general ward while all other 


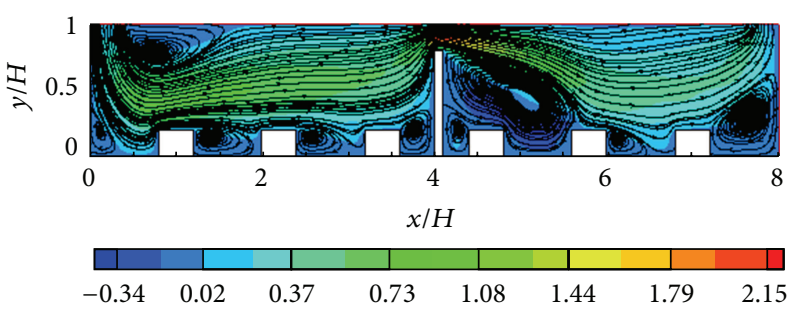

(a)

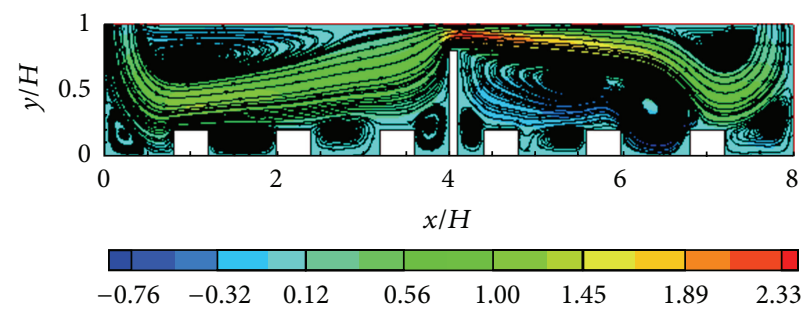

(b)

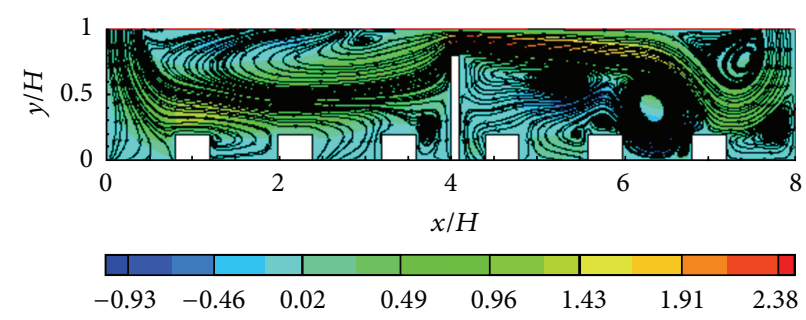

(c)

Figure 5: Streamline patterns of Case II for (a) $\operatorname{Re}=100$, (b) $\operatorname{Re}=250$, and (c) $\operatorname{Re}=350$.

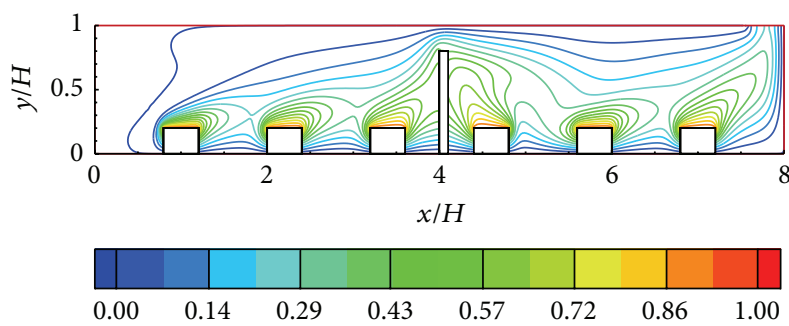

(a)

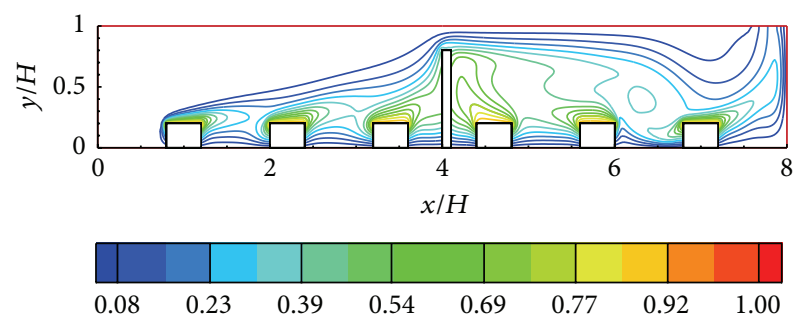

(b)

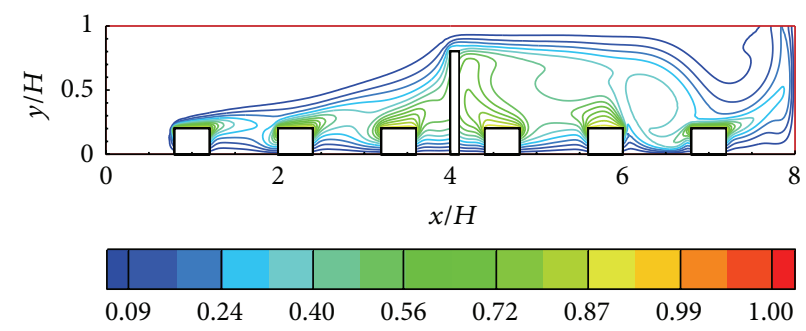

(c)

Figure 6: Isotherms of Case II for (a) $\operatorname{Re}=100$, (b) $\operatorname{Re}=250$, and (c) $\operatorname{Re}=350$.

schematic measurements have been kept the same, as shown in Figure 1. The lattice size of partition is $(5 \times 40) \sim(x \times y)$ and it is placed just after the first three blocks (beds). Simulations have been carried out for the same three Reynolds numbers. After placing a partition just like in Figure 5, recirculation is seen in Figure 5 and it shows much better result than the previous simulations. The airflow pattern is clearer this time which shows that air moves inward smoothly, passes the partition naturally without overlapping it, and nicely flows out through the outlet creating its usual recirculation near the inlet, between the blocks and near the outlet. Unlike earlier, the recirculations now are larger and more frequent, particularly after crossing the partition. For $\operatorname{Re}=100$, a large air circulation can be noticed between blocks 4 and 5 and in case of $\operatorname{Re}=250$, an even larger recirculation has appeared between blocks 5 and 6 along with a newly emerged one just beside the outlet. As for $\mathrm{Re}=350$, with the increase in convective air current more chaotic flow dynamics can be noticed before the partition appears. The airflow pattern in this region indicates that, in case of mixed convection for $\operatorname{Re}=350$, the air stays in transitional state which shows both the laminar characteristics of natural convection and the turbulent nature of forced convection, thereby representing forced convection. Moreover, after placing the partition, the peak values of the contour have risen to 2.15 from $1.08,2.33$ from 1.26, and 2.38 from 1.30 for $R e=100, R e=250$, and $\operatorname{Re}=350$, respectively.

Figure 6 presents the isotherms for this situation. Like in previous case, here also the top surfaces of the blocks are kept heated to represent patients on beds and the spaces between 


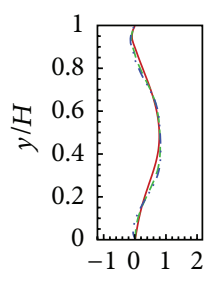

$u / U$

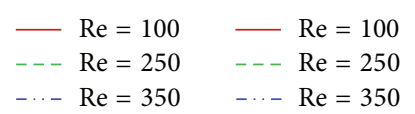

(a)

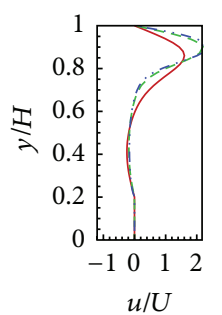

$-\operatorname{Re}=100$
$--\operatorname{Re}=250$
$-\cdots-\operatorname{Re}=350$

(h)

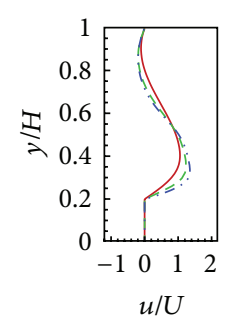

(b)

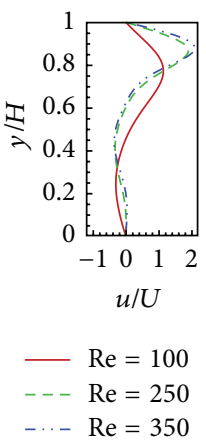

(i)

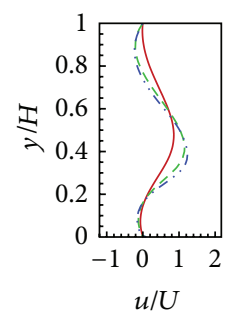

$-\operatorname{Re}=100$

$---\operatorname{Re}=250$

- - $\operatorname{Re}=350$

(c)

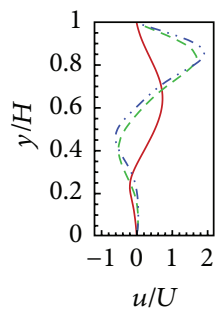

$-\operatorname{Re}=100$
$--\operatorname{Re}=250$
$-\cdots-\operatorname{Re}=350$

(j)
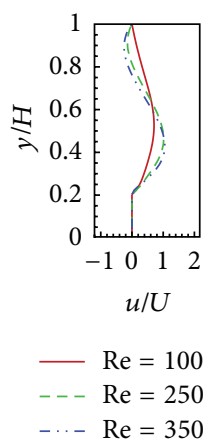

(d)

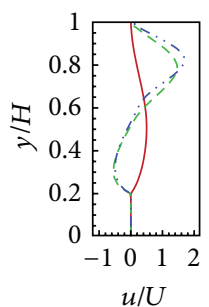

$\begin{aligned}- & \operatorname{Re}=100 \\ --- & \operatorname{Re}=250 \\ -\cdots- & \operatorname{Re}=350\end{aligned}$

(k)

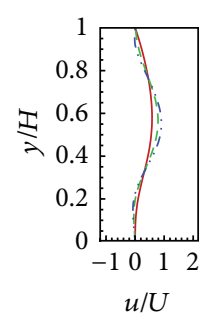

$-\operatorname{Re}=100$
$--\operatorname{Re}=250$
$-\cdots \operatorname{Re}=350$

(e)

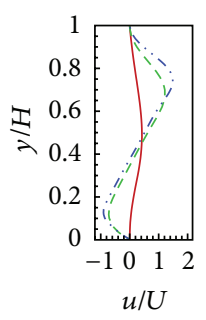

$-\operatorname{Re}=100$
$--\operatorname{Re}=250$
$-\cdots-\operatorname{Re}=350$

(1)

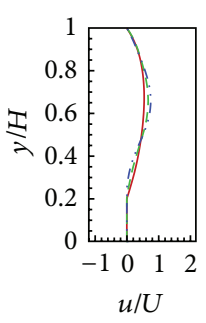

$\begin{aligned}- & \operatorname{Re}=100 \\ --- & \operatorname{Re}=250 \\ -\cdots-\operatorname{Re} & =350\end{aligned}$

(f)

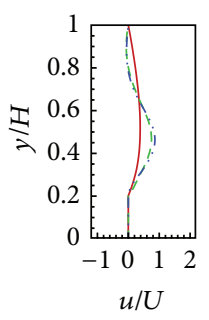

$-\operatorname{Re}=100$
$--\operatorname{Re}=250$
$-\cdots-\operatorname{Re}=350$

(m)

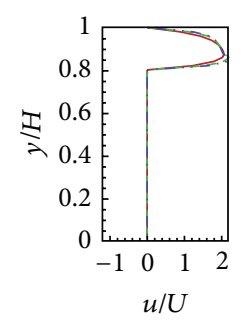

- $\operatorname{Re}=100$

$--\operatorname{Re}=250$

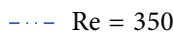

(g)

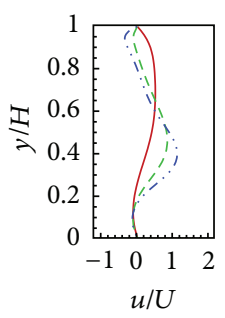

$\begin{aligned}- & \operatorname{Re}=100 \\ -- & \mathrm{Re}=250 \\ -\cdots- & \mathrm{Re}=350\end{aligned}$

(n)

FIGURE 7: $u / U$ velocity profiles in Case II for the different Re at different positions of horizontal locations (a) $x / H=0.5,(\mathrm{~b}) x / H=1,(\mathrm{c})$ $x / H=1.5$, (d) $x / H=2$, (e) $x / H=3$, (f) $x / H=3.5$, (g) $x / H=4$, (h) $x / H=4.5$, (i) $x / H=5,(\mathrm{j}) x / H=5.5,(\mathrm{k}) x / H=6,(\mathrm{l}) x / H=6.5,(\mathrm{~m})$ $x / H=7$, and (n) $x / H=7.5$.

the blocks along with the partition are kept cold. The presence of the partition does affect the airflow characteristics as well as heat transfer phenomenon, which has been discussed in detail in the heat transfer part. Pr remains the same.

In Figure 7, the $U$ velocity profiles at different locations of $x$ are discussed for the same three Re. This time the results show more curvy lines throughout the whole experiment due to the obstacle caused because of the partition. One of the obvious differences worth mentioning is in Figure $7(\mathrm{~g})$ when the air faces the partition. At this point, a long vertical line with a narrow parabolic curve at the top is shown representing the height of the partition whereas the curved part illustrates that the air is crossing the partition. Even in Figure 7(h), the graph still maintains its parabolic shape and continues this pattern throughout till the end. Another noticeable change can be seen in Figures $7(\mathrm{j}), 7(\mathrm{k})$, and $7(\mathrm{l})$, at $x=5.5, x=6$, and $x=6.5$, respectively, where the bents are more irregular than the previous case. This is because at these locations large recirculations have formed due to the partition, as shown in Figure 5.

According to the $U$ and $V$ centerline velocity distribution plots in Figures $8(\mathrm{a})$ and $8(\mathrm{~b})$, respectively, there is a constriction in the middle of graph. This represents the partition that actually works like a wall where the velocity plots cease, just like the vertical walls in the extreme left and right sides. One possible advantage of this partition is that the airflow can be controlled if the air enters with a high speed through the inlet. Also it is noticeable in Figures $8(\mathrm{a})$ and 8 (b) that, unlike the previous case, the partition helps to maintain the air velocity at a constant level until it exits out through the outlet. The $V$ velocity still drops to negative range from zero at the beginning due to downward fall of air through the inlet and ascends to zero again where it maintains its constant velocity. The graphs are more chaotic after crossing the partition due to the recirculations shown in the contour map. The temperature plot in Figure 8(c) starts just like that of the previous situation, but this time instead of becoming constant after a certain level, the graph climbs up the partition, crosses it, and then drops again, eventually decreasing to zero at $x=8$. The rise of airflow against the partition also results in the increase in temperature at this point, therefore, the steep in the figure.

5.4. Case Study III: One Inlet and One Outlet with Two Partitions. This case study has been investigated by further modifying the proposed model adding another partition in the ward. It was done to keep patients from being exposed into more air. Each partition is placed every after two blocks (beds). Both the partitions are of the same dimension, that is, $(5 \times 40) \sim(x \times y)$ lattice size, and all other measurements are kept the same as previous situations. Simulations and analysis of this case have also been carried out for the same three Re values. Streamlines pattern of Figure 9 obtained after adding another partition shows that the size and the number of recirculations increase more than the last observation. Unlike Case II, now two large recirculations have formed 

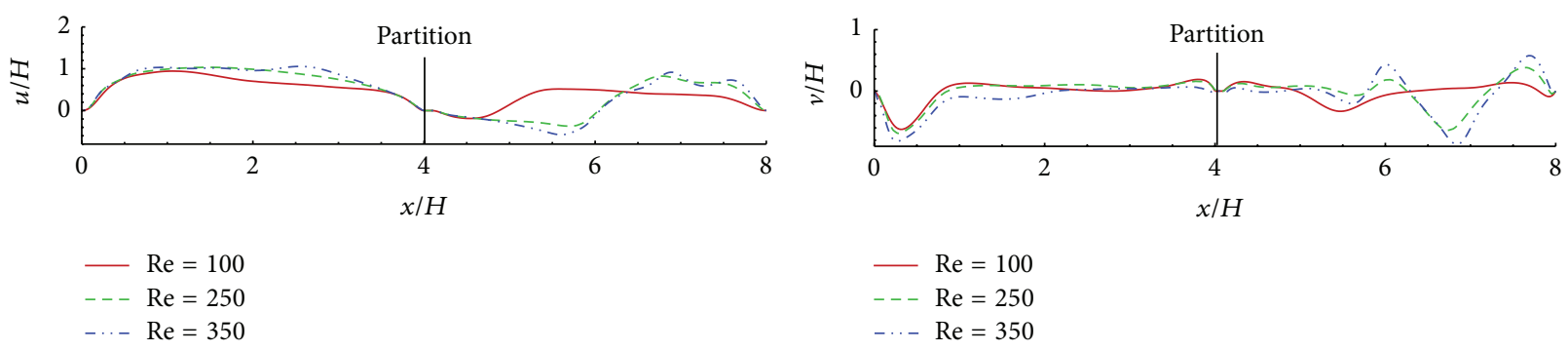

(a)

(b)

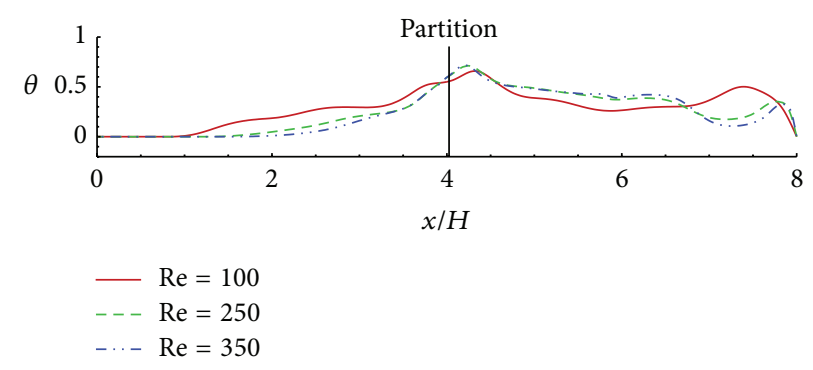

(c)

FIgURE 8: In Case II for $\operatorname{Re}=100,250$ and $\operatorname{Re}=350$ the velocity distributions are (a) $u / H$ at mid- $y$ and (b) $v / H$ at mid- $y$, and temperature distribution is (c) $\theta$ at mid- $y$.

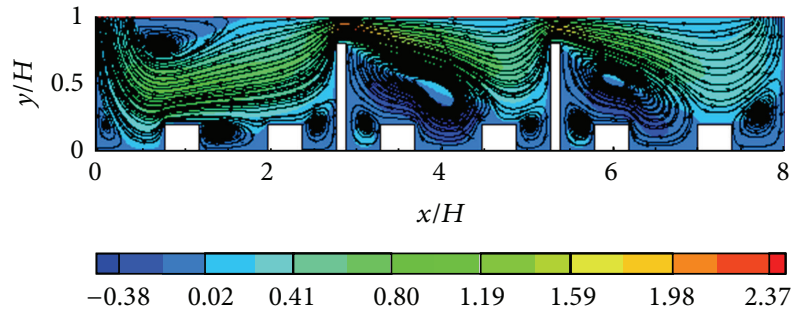

(a)

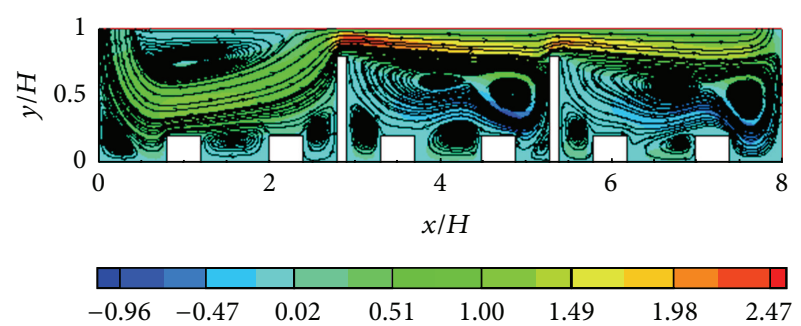

(b)

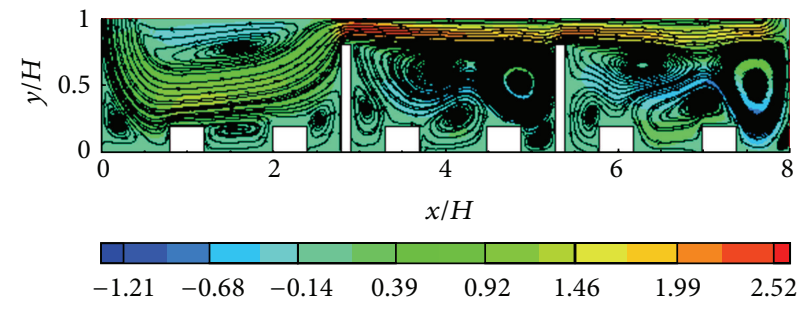

(c)

Figure 9: Streamline patterns of Case III for (a) $\operatorname{Re}=100$, (b) $\operatorname{Re}=250$, and (c) $\operatorname{Re}=350$.

for the corresponding experiments with each Re. Even the maximum and minimum legend values have become wider than the previous situation; for example, for $\mathrm{Re}=100$ the 2.15 value has increased to 2.37. For $\operatorname{Re}=250$ and $\operatorname{Re}=350$ the uppermost values have risen to 2.47 and 2.52 from 2.33 and 2.38, respectively. Due to bounce-back condition, the air is now forming more recirculations against the walls and between the blocks. This augmentation of values and recirculations due to buoyancy effect is visible for every increment of Re values and addition of obstacles such as partition.

The generated results of isotherms in Figure 10 give a visual idea how the heat is transferred from the blocks and passes through the outlet. Like the other cases, only the surfaces of the blocks are heated to be considered as patients who are continuously releasing heat. Everything remains the same like previous cases.

Figure 11 provides the $U$ velocity profiles for different positions of $x$. According to this the graph characteristic for a partition can be seen in Figure 11(e) at $x=3$ and Figure $11(\mathrm{j})$ at $x=5.5$, indicating the presence of partitions at these two locations. Apart from this, at $x=5$ and 7.5 in Figures 11(i) and 11(n), respectively, the parabolic shapes are more curvy than the profiles at other positions caused due to recirculations in vector plots of $\mathrm{Re}=250$ and $\mathrm{Re}=350$. 

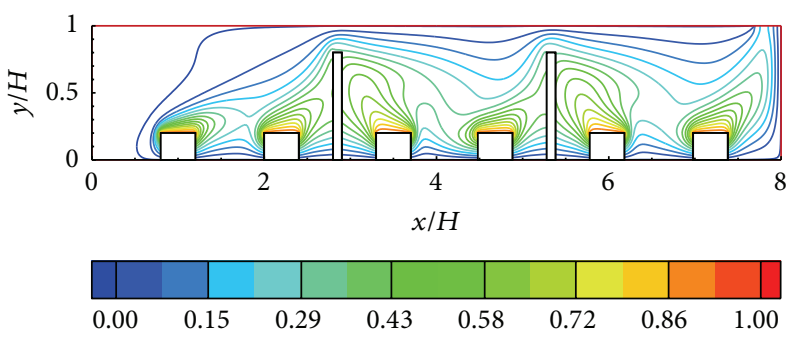

(a)
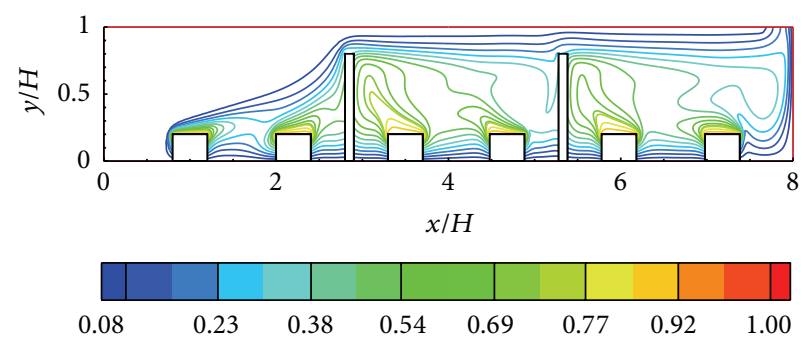

(b)
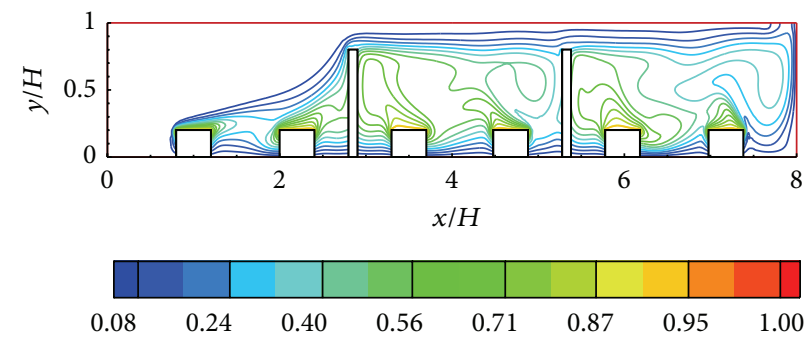

(c)

Figure 10: Isotherms of Case III for (a) $\operatorname{Re}=100$, (b) $\operatorname{Re}=250$, and (c) $\operatorname{Re}=350$.

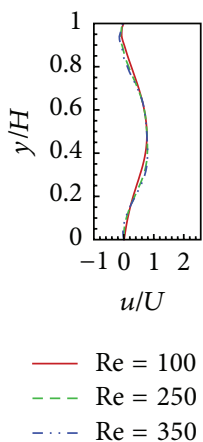

(a)

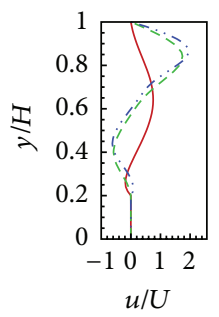

$$
\begin{aligned}
& -\mathrm{Re}=100 \\
& ---\operatorname{Re}=250 \\
& -\cdots-\operatorname{Re}=350
\end{aligned}
$$

(h)

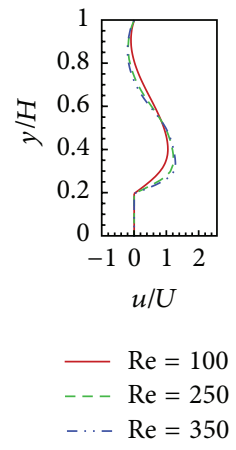

(b)

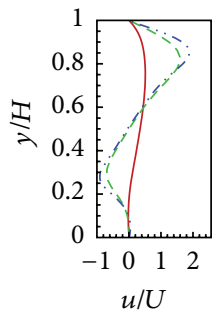

$$
\begin{aligned}
& -\mathrm{Re}=100 \\
& --\mathrm{Re}=250 \\
& -\cdots \mathrm{Re}=350
\end{aligned}
$$

(i)

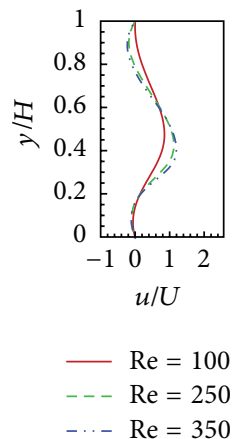

(c)

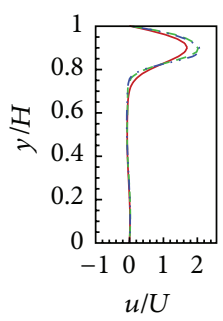

$$
\begin{aligned}
& -\mathrm{Re}=100 \\
& ---\mathrm{Re}=250 \\
& -\cdots-\mathrm{Re}=350
\end{aligned}
$$

(j)

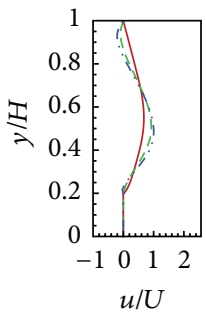

$-\operatorname{Re}=100$

$--\operatorname{Re}=250$

$-\cdots-\operatorname{Re}=350$

(d)

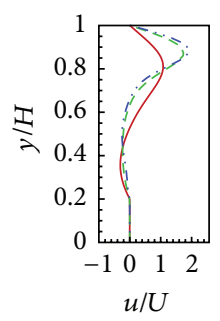

$$
\begin{aligned}
& -\mathrm{Re}=100 \\
& \text { - - } \mathrm{Re}=250 \\
& \text {-.. } \mathrm{Re}=350
\end{aligned}
$$

(k)

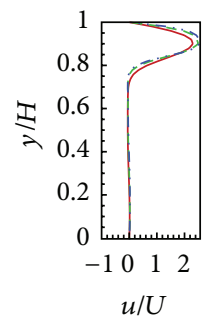

$-\operatorname{Re}=100$

$---\operatorname{Re}=250$

-..- $\mathrm{Re}=350$

(e)

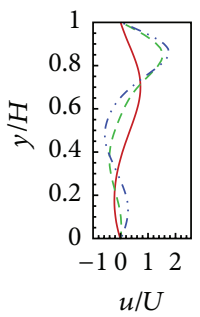

$-\mathrm{Re}=100$
$---\mathrm{Re}=250$
$\ldots-\mathrm{Re}=350$

(1)

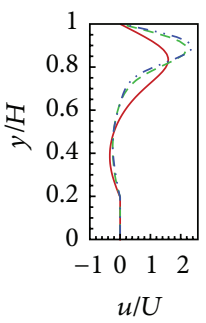

$-\operatorname{Re}=100$

$---\operatorname{Re}=250$

$-\cdots-\operatorname{Re}=350$

(f)

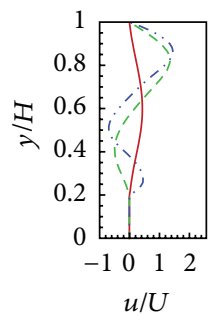

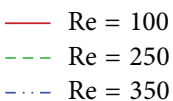

(m)
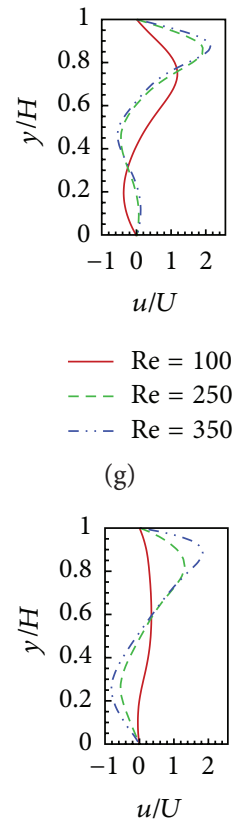

(g)

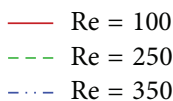

(n)

FIGURE 11: $u / U$ velocity profiles in Case III for the different Re at different positions of horizontal locations (a) $x / H=0.5$, (b) $x / H=1,(\mathrm{c})$ $x / H=1.5$, (d) $x / H=2$, (e) $x / H=3$, (f) $x / H=3.5$, (g) $x / H=4$, (h) $x / H=4.5$, (i) $x / H=5,(\mathrm{j}) x / H=5.5,(\mathrm{k}) x / H=6,(\mathrm{l}) x / H=6.5,(\mathrm{~m})$ $x / H=7$, and (n) $x / H=7.5$.

Figures 12(a) and 12(b) illustrate $U$ and $V$ velocity distribution curves in mid- $y$ and Figure 12(c) shows the temperature profile at mid- $y$. All of these three plots have one thing in common that is also different than the previous case. In these plots there are two constrictions, instead of one, where the velocities or the temperature curve ceases. This is the location where the two partitions are present. But after crossing these obstacles the respective graphs continue until $x=8$. The temperature plot in Figure 12(c) has now two steep regions due to the partitions. 


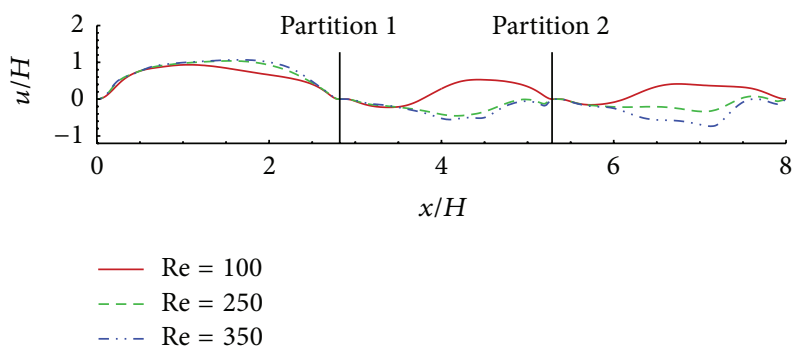

(a)

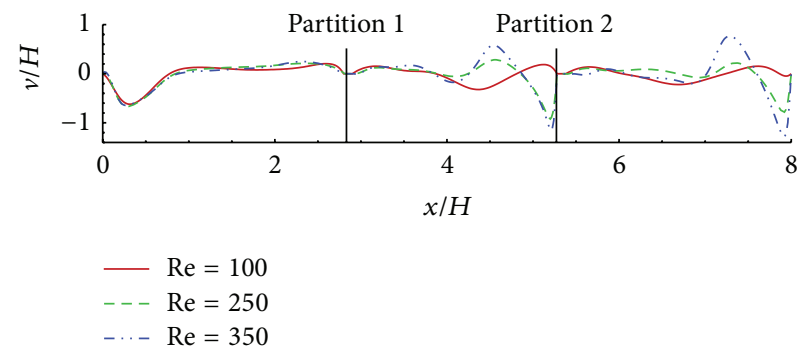

(b)

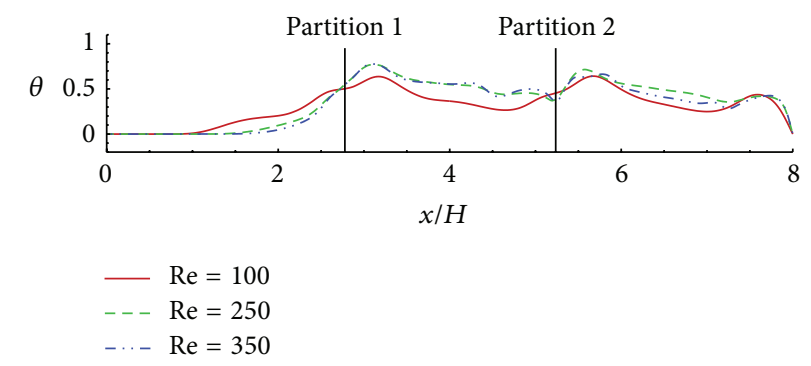

(c)

FIGURE 12: In Case III for $\operatorname{Re}=100,250$ and $\operatorname{Re}=350$ the velocity distributions are (a) $u / H$ at mid- $y$ and (b) $v / H$ at mid- $y$, and temperature distribution is (c) $\theta$ at mid- $y$.

5.5. Calculation of Rate of Heat Transfer. In heat transfer at a boundary (surface) within a fluid, the Nusselt number $(\mathrm{Nu})$ is the ratio of convective to conductive heat transfer across (normal to) the boundary. Here, convection includes both advection and diffusion procedures. The convection and conduction heat flows are parallel to each other and to the surface normal of the boundary surface and are all perpendicular to the mean fluid flow in the simple case. This is denoted as [32]

$$
\mathrm{Nu}_{L}=\frac{h_{t} L}{k}
$$

where $h_{t}$ is the convective heat transfer coefficient of the flow, $L$ is the characteristic length, and $k$ is the thermal conductivity of the fluid.

However, this section discusses the average rate of change of heat transfer obtained for different Re. This rate is expressed as average Nusselt number, $\overline{\mathrm{Nu}}$, for each case study in Tables 2, 3, and 4. The tables also show generated local Nusselt number, $\mathrm{Nu}$, that follows the expression below:

$$
\mathrm{Nu}(x)=-\left.\frac{\partial \theta}{\partial y}\right|_{y=y_{2}},
$$

where $y_{2}$ is the upper surface of each block.

Average, $\overline{\mathrm{Nu}}$, is calculated by integrating the above relation over the entire range of interest and thus the resulting equation becomes

$$
\overline{\mathrm{Nu}}=\frac{1}{x_{2}-x_{1}} \int_{x_{1}}^{x_{2}} \mathrm{Nu}(x) d x .
$$

Here, $\left(x_{2}-x_{1}\right)$ is the length of each block.
For the first investigation, both the individual and average Nu obtained in Table 2 show a rising trend for each increasing Re. Since block 1 is the nearest to the inlet, it always has the highest rate of heat transfer while block 6 has the lowest value as it is located farthest from the inlet.

After placing the partition in the middle, the rate of heat transfer shown in Table 3 changes dramatically. Like Table 2, the patient at block 1 is releasing most heat for all three Re and it keeps reducing until block 5. At block 5, the values of both individual $\overline{\mathrm{Nu}}$ and total $\overline{\mathrm{Nu}}$ increase for $\mathrm{Re}=250$ and $\mathrm{Re}=350$, but for $\mathrm{Re}=100$, this type of airflow pattern is seen at block 4 . The large recirculations were seen earlier in Figure 5. For $\mathrm{Re}=100$, recirculation is more over block 4 and that is the reason why, at block 4 , individual $\overline{\mathrm{Nu}}$ and total $\overline{\mathrm{Nu}}$ have greater values than those of $\mathrm{Re}=250$ and $\mathrm{Re}=350 . \overline{\mathrm{Nu}}$ is 1.5341 at block 4 and, for the same block, these values are 1.3628 and 1.4032, respectively, for $\operatorname{Re}=250$ and $\operatorname{Re}=350$. On the other hand, if $\overline{\mathrm{Nu}}$ at block 5 are observed, $\mathrm{Re}=250$ and $\mathrm{Re}=350$ lead the race. As per Table 3, $\overline{\mathrm{Nu}}$ are 2.0111, 2.1598, and 2.7535 for three Re. The spike in the values of $\operatorname{Re}=250$ and $\operatorname{Re}=350$ was due to chaotic flows over block 5 in Figure 5. If changes in total $\overline{\mathrm{Nu}}$ are observed, the values increase rapidly for an increase in Re.

For Case Study III, the shape of recirculation gets bigger due to increased Re. Above block 1, the recirculation zone comes into view and, due to that reason, $\overline{\mathrm{Nu}}$ has the biggest edge in this situation. But as the air has tendency to pass the first partition, it moves slightly upward and that is why patient at block 2 is getting less airflow. The heat transfer rate also falls. After passing the first partition, the airflow gets its space and leads to recirculation near block 3 for $\mathrm{Re}=100$. Meanwhile, for $\operatorname{Re}=250$ and $\operatorname{Re}=350$, patients on block 4 get most air. More air means more heat transfer and that is 
TABLE 2: Summary of average Nusselt numbers $\overline{\mathrm{Nu}}$ for six blocks individually and in total for three Reynolds numbers at $\mathrm{Pr}=0.71$ in case of without partition.

\begin{tabular}{lccccccc}
\hline \multirow{2}{*}{ Re } & & \multicolumn{4}{c}{$\overline{\mathrm{Nu}}$ (individually) } & \multicolumn{1}{c}{ Nu (total) } \\
& Block 1 & Block 2 & Block 3 & Block 4 & Block 5 & 1.4486 & 1.5368 \\
100 & 3.0164 & 2.0366 & 1.7990 & 1.6667 & 1.5695 & 1.8028 \\
250 & 4.6238 & 2.9266 & 2.2996 & 2.1784 & 2.0573 & 15.8885 \\
350 & 5.4359 & 2.0344 & 2.4841 & 2.2300 & 2.1352 & 1.7329 & 17.5970 \\
\hline
\end{tabular}

TABLE 3: Summary of average Nusselt numbers $\overline{\mathrm{Nu}}$ for six blocks individually and in total for three Reynolds numbers at Pr $=0.71$ in case of with partition.

\begin{tabular}{|c|c|c|c|c|c|c|c|}
\hline \multirow{2}{*}{$\operatorname{Re}$} & \multicolumn{6}{|c|}{$\overline{\mathrm{Nu}}$ (individually) } & \multirow{2}{*}{$\overline{\mathrm{Nu}}$ (total) } \\
\hline & Block 1 & Block 2 & Block 3 & Block 4 & Block 5 & Block 6 & \\
\hline 100 & 3.2979 & 2.0344 & 1.6115 & 1.5341 & 2.0111 & 1.6124 & 12.1014 \\
\hline 250 & 5.0273 & 2.9488 & 1.7955 & 1.3628 & 2.1598 & 3.8673 & 17.1615 \\
\hline 350 & 5.8293 & 3.6676 & 1.8670 & 1.4032 & 2.7535 & 5.3320 & 20.8527 \\
\hline
\end{tabular}

TABLE 4: Summary of average Nusselt numbers $\overline{\mathrm{Nu}}$ for six blocks individually and in total for three Reynolds numbers at $\mathrm{Pr}=0.71$ in case of two partitions.

\begin{tabular}{|c|c|c|c|c|c|c|c|}
\hline \multirow{2}{*}{$\operatorname{Re}$} & \multicolumn{6}{|c|}{$\overline{\mathrm{Nu}}$ (individually) } & \multirow{2}{*}{$\overline{\mathrm{Nu}}$ (total } \\
\hline & Block 1 & Block 2 & Block 3 & Block 4 & Block 5 & Block 6 & \\
\hline 100 & 3.2791 & 1.8265 & 1.6086 & 1.8914 & 1.5810 & 1.7583 & 11.9449 \\
\hline 250 & 4.9303 & 2.2066 & 1.1352 & 2.5811 & 1.3338 & 2.4044 & 14.5915 \\
\hline 350 & 5.7620 & 2.4463 & 1.1924 & 2.9056 & 1.2632 & 2.7495 & 16.3191 \\
\hline
\end{tabular}

why $\overline{\mathrm{Nu}}$ are 2.5811 and 2.9056 in terms of block 4 for $\mathrm{Re}=$ 250,350 . However, the change in the values of $\overline{\mathrm{Nu}}$ repeats in terms of block 5 . For $\mathrm{Re}=100$, patient at block 5 gets most air and that is also due to vorticity, which is seen in Figure 9. For two other Re, these recirculations appear over block 6, which also lead to an increase in $\overline{\mathrm{Nu}}$ as per Table 4 .

Comparing the results after analyzing Tables 2, 3, and 4, few statements can be made. Heat transfer rate is at its highest level when one partition is present. For example, when there is not any partition, total $\overline{\mathrm{Nu}}$ is 15.8885 for $\mathrm{Re}=250$ and it rises to 17.1615 when one partition is present. However, placing two partitions create one extra obstacle for airflow and $\overline{\mathrm{Nu}}$ decreases to 14.5915 . Same variations can be observed for $\operatorname{Re}=100$ and $\operatorname{Re}=350$ as well.

The finding of three case studies can be related to the need of airflow of hospital patients. For instance, if a hospital ward does not have any obstacle or partition between any bed, patient who is in need of most airflow should be put on block (bed) 1. If anyone needs less air due to fever or is suffering from any type of airborne disease or germs, he or she should be kept at block 6 or on any bed which is farthest to the inlet.

Consequently, if the ward has one partition in the middle (which is pretty common in hospital nowadays), both blocks (beds) 1 and 2 will be just fine for more air. If disease is related to air, these two beds in particular should be avoided. For moderate airflow, any bed or block after the first two should be considered.

Last but not least, if three different zones are available in the ward due to two partitions, any bed between 3 and
6 should be okay for normal airflow. Blocks (beds) 1 and 2 should be kept for patients who are suffering from acute temperature related disease. By any chance, if none of those beds are available, block (bed) 4 will be a pretty good replacement.

\section{Local Reynolds Number}

Local Reynolds numbers $\left(\operatorname{Re}_{l}\right)$ for all obstacles have been computed at the mid of the gap between block and top wall for Case II (with one partition) at $\mathrm{Re}=100$. They are 61.54 for block 1, 35.34 for block 2, 25.54 for block 3, 36.93 for partition, 16.32 for block 4, 24.54 for block 5, and 32.19 for block 6 . The above results demonstrate that as the air enters the domain and flows far away from the inlet, the inlet air velocity also reduces and, consequently, the local $\mathrm{Re}_{l}$ values also decrease. Block 1 has the highest local $\mathrm{Re}_{l}$ value since the inlet velocity is maximum at this position. After gradual decline of the numerals, block 4 has negative local $\mathrm{Re}_{l}$ due to the negative velocity of the recirculation zone. The values then increase as the air flows up towards the outlet but cannot attain the maximum value due to the distance from the inlet.

\section{Conclusion}

In this paper, the study of airflow on mixed convection flow inside a hospital ward has been analyzed using the Lattice Boltzmann Method. The changes in the patterns of airflow have been observed in three different case studies. The 
code validation has been carried out for three different Re and agreement has been shown as well. In the case studies, LBM was able to capture the convective structure as the air flowed over the room and even when the partition was present. It was found that the heat transfer process and flow characteristics depend on different Re. Moreover, the presence of the partition in each case was found to have significance on the pattern of airflow in both streamlines and isotherms on a particular Ri and Gr. Some conclusions are summarized as follows:

(a) A proper code validation with previous numerical investigations implies that Lattice Boltzmann Method is indeed an appropriate method for studying mixed convective airflow.

(b) Generally, the increase in Reynolds number resulted in augmentation of heat transfer. The pattern of airflow also changed.

(c) As the Reynolds number increases, the Mach number decreases. The Mach number cannot be more than 0.3 to satisfy the condition of flow in incompressible fluid.

(d) Since local Re is directly proportional to the velocity of inlet flow, therefore, as the air gradually flows away from the inlet, the flow velocity reduces for which local Re also decreases.

(e) Placing partition between the blocks or beds had effects on the airflow structure and for different cases, the results were different.

(f) The most effective rate of heat transfer was found when one partition was present, which were due to recirculations in the contours.

(g) Influence of two partitions on heat transfer was less for all three Reynolds numbers, which indicates that air did not get enough space to flow freely and that led to a fall in heat transfer rate.

(h) Patients who are in need of most air should be kept near the inlet and patients who do not need to be exposed directly to air should be moved near the outlet.

\section{Nomenclature}

\section{English Symbols}

$a:$ Height of the partition
$b:$ Width of the partition
$c:$ Lattice speed
$\bar{e}_{i}:$ Particle velocity
$F:$ External forces
$f:$ Distribution function for velocity
$f^{\text {eq. }}:$ Equilibrium distribution function for velocity
Gr: Grashof number
$G_{y}:$ Gravitational acceleration in $y$-direction
$g:$ Distribution function for temperature
$g^{\text {eq. }}:$ Equilibrium distribution function for temperature
$H:$ Height of the hospital ward
$h: \quad$ Height of each block

$h_{t}$ : Convective heat transfer coefficient of the flow

$k$ : $\quad$ Thermal conductivity of the fluid

L: $\quad$ Length of the hospital ward

$l$ : $\quad$ Length of each block

Ma: $\quad$ Mach number

$N$ : $\quad$ Number of lattices parallel to $y$-direction

$\mathrm{Nu}$ Local Nusselt number

$\overline{\mathrm{Nu}}$ : Average Nusselt number

n: $\quad$ Iteration index

Pr: $\quad$ Prandtl number

Re: Reynolds number

Ri: $\quad$ Richardson number

$T$ : $\quad$ Temperature of the fluid

$T_{H}, T_{W}$ : Hot wall temperature

$T_{C}$ : Cold wall temperature

$t: \quad$ Time

$\bar{u}: \quad$ Velocity vector

$u$ : $\quad$ Velocity component along $x$-direction

$v: \quad$ Velocity component along $y$-direction

$U$ : Bulk velocity

$w_{i}$ : Weighted factor

$x, X: \quad$ Horizontal axial coordinate

$y, Y: \quad$ Vertical axial coordinate.

\section{Greek Symbols}

$\alpha$ : Thermal diffusivity

$\mu$ : Dynamic viscosity of the fluid

$\nu$ : Kinematic viscosity

$\rho$ : Density

$\tau_{\nu}$ : Single-relaxation time based on $\nu$

$\tau_{\alpha}$ : Single-relaxation time based on $\alpha$

$\theta$ : Nondimensional temperature

$\phi$ : Generic variable

$\Omega$ : Collision operator

$\bar{\nabla}$ : Gradient operator.

\section{Competing Interests}

The authors declare that they have no competing interests.

\section{References}

[1] C. K. Cha and Y. Jaluria, "Recirculating mixed convection flow for energy extraction," International Journal of Heat and Mass Transfer, vol. 27, no. 10, pp. 1801-1812, 1984.

[2] F. J. K. Ideriah, "Prediction of turbulent cavity flow driven by buoyancy and shear," Journal of Mechanical Engineering Science, vol. 22, no. 6, pp. 287-295, 1980.

[3] J. Imberger and P. F. Hamblin, "Dynamics of lakes, reservoirs, and cooling ponds," Annual Review of Fluid Mechanics, vol. 14, pp. 153-187, 1982.

[4] H. Huang, M. C. Sukop, and X. Lu, Multiphase Lattice Boltzmann Methods: Theory and Application, John Wiley \& Sons, New York, NY, USA, 2015.

[5] B. Hasslacher, Y. Pomeau, and U. Frisch, "Lattice-gas automata for the Navier-Stokes equation," Physical Review Letters, vol. 56, no. 14 , pp. $1505-1508,1986$. 
[6] G. Vahala, P. Pavlo, L. Vahala, and N. S. Martys, "Thermal lattice-boltzmann models (TLBM) for compressible flows," International Journal of Modern Physics C, vol. 9, no. 8, pp. 12471261, 1998.

[7] Y. Peng, C. Shu, and Y. T. Chew, "Simplified thermal lattice Boltzmann model for incompressible thermal flows," Physical Review E, vol. 68, no. 2, Article ID 026701, 2003.

[8] T. S. Lee, H. Huang, and C. Shu, "An axisymmetric incompressible lattice BGK model for simulation of the pulsatile flow in a circular pipe," International Journal for Numerical Methods in Fluids, vol. 49, no. 1, pp. 99-116, 2005.

[9] N. A. C. Sidik, "The development of thermal lattice Boltzmann models in incompressible limit," Malaysian Journal of Fundamental and Applied Sciences, vol. 3, no. 2, pp. 193-202, 2008.

[10] B. Mondal and X. Li, "Effect of volumetric radiation on natural convection in a square cavity using lattice Boltzmann method with non-uniform lattices," International Journal of Heat and Mass Transfer, vol. 53, no. 21-22, pp. 4935-4948, 2010.

[11] M. Szucki and J. S. Suchy, "A method for taking into account local viscosity changes in single relaxation time the lattice Boltzmann model," Metallurgy and Foundry Engineering, vol. 38, pp. 33-42, 2012.

[12] S. Chen and G. D. Doolen, "Lattice Boltzmann method for fluid flows," Annual Review of Fluid Mechanics, vol. 30, no. 1, pp. 329364, 1998.

[13] G. Breyiannis and D. Valougeorgis, "Lattice kinetic simulations in three-dimensional magnetohydrodynamics," Physical Review E, vol. 69, no. 6, Article ID 065702, 2004.

[14] I. Halliday, L. A. Hammond, C. M. Care, K. Good, and A. Stevens, "Lattice Boltzmann equation hydrodynamics," Physical Review E, vol. 64, no. 1 I, Article ID 011208, 2001.

[15] C. S. N. Azwadi and T. Tanahashi, "Development of 2-D and 3-D double-population thermal lattice boltzmann models," Matematika, vol. 24, no. 1, pp. 53-66, 2008.

[16] B. Crouse, M. Krafczyk, S. Kühner, E. Rank, and C. Van Treeck, "Indoor air flow analysis based on lattice Boltzmann methods," Energy and Buildings, vol. 34, no. 9, pp. 941-949, 2002.

[17] Z. Zhang, X. Chen, S. Mazumdar, T. Zhang, and Q. Chen, "Experimental and numerical investigation of airflow and contaminant transport in an airliner cabin mockup," Building and Environment, vol. 44, no. 1, pp. 85-94, 2009.

[18] S. J. Zhang and C. X. Lin, "Application of lattice Boltzmann method in indoor airflow simulation," HVAC \& $R$ Research, vol. 16, no. 6, pp. 825-841, 2010.

[19] J. Liu, H. Wang, and W. Wen, "Numerical simulation on a horizontal airflow for airborne particles control in hospital operating room," Building and Environment, vol. 44, no. 11, pp. 2284-2289, 2009.

[20] A. Watzinger and D. G. Johnson, "Wärmeübertragung von wasser an rohrwand bei senkrechter strömung im übergangsgebiet zwischen laminarer und turbulenter strömung," Forschung auf dem Gebiet des Ingenieurwesens A, vol. 10, no. 4, pp. 182-196, 1939.

[21] A. K. Prasad and J. R. Koseff, "Combined forced and natural convection heat transfer in a deep lid-driven cavity flow," International Journal of Heat and Fluid Flow, vol. 17, no. 5, pp. 460-467, 1996.

[22] H. Xu, R. Xiao, F. Karimi, M. Yang, and Y. Zhang, "Numerical study of double diffusive mixed convection around a heated cylinder in an enclosure," International Journal of Thermal Sciences, vol. 78, pp. 169-181, 2014.
[23] S. A. Al-Sanea, M. F. Zedan, and M. B. Al-Harbi, "Effect of supply Reynolds number and room aspect ratio on flow and ceiling heat-transfer coefficient for mixing ventilation," International Journal of Thermal Sciences, vol. 54, pp. 176-187, 2012.

[24] F.-Y. Zhao, D. Liu, and G.-F. Tang, "Multiple steady fluid flows in a slot-ventilated enclosure," International Journal of Heat and Fluid Flow, vol. 29, no. 5, pp. 1295-1308, 2008.

[25] K. M. Khanafer and A. J. Chamkha, "Mixed convection flow in a lid-driven enclosure filled with a fluid-saturated porous medium," International Journal of Heat and Mass Transfer, vol. 42, no. 13, pp. 2465-2481, 1999.

[26] G. H. R. Kefayati, S. F. Hosseinizadeh, M. Gorji, and H. Sajjadi, "Lattice Boltzmann simulation of natural convection in an open enclosure subjugated to water/copper nanofluid," International Journal of Thermal Sciences, vol. 52, no. 1, pp. 91-101, 2012.

[27] H. Lee and H. B. Awbi, "Effect of internal partitioning on room air quality with mixing ventilation-statistical analysis," Renewable Energy, vol. 29, no. 10, pp. 1721-1732, 2004.

[28] Y. B. Bao and J. Meskas, Lattice Boltzmann Method for Fluid Simulations, Courant Institute of Mathematical Sciences, New York, NY, USA, 2011.

[29] H. N. Dixit and V. Babu, "Simulation of high Rayleigh number natural convection in a square cavity using the lattice Boltzmann method," International Journal of Heat and Mass Transfer, vol. 49, no. 3-4, pp. 727-739, 2006.

[30] R. Huang, H. Wu, and P. Cheng, "A new lattice Boltzmann model for solid-liquid phase change," International Journal of Heat and Mass Transfer, vol. 59, no. 1, pp. 295-301, 2013.

[31] Y. Xuan and Z. Yao, "Lattice boltzmann model for nanofluids," Heat and Mass Transfer, vol. 41, no. 3, pp. 199-205, 2005.

[32] G. R. Kefayati, M. Gorji-Bandpy, H. Sajjadi, and D. D. Ganji, "Lattice Boltzmann simulation of MHD mixed convection in a lid-driven square cavity with linearly heated wall," Scientia Iranica, vol. 19, no. 4, pp. 1053-1065, 2012.

[33] Q. Zou and X. He, "On pressure and velocity boundary conditions for the lattice Boltzmann BGK model," Physics of Fluids, vol. 9, no. 6, pp. 1591-1598, 1997.

[34] A. A. Mohamad and A. Kuzmin, "A critical evaluation of force term in lattice Boltzmann method, natural convection problem," International Journal of Heat and Mass Transfer, vol. 53, no. 5-6, pp. 990-996, 2010.

[35] R. Iwatsu, J. M. Hyun, and K. Kuwahara, "Mixed convection in a driven cavity with a stable vertical temperature gradient," International Journal of Heat and Mass Transfer, vol. 36, no. 6, pp. 1601-1608, 1993.

[36] K. M. Khanafer, A. M. Al-Amiri, and I. Pop, "Numerical simulation of unsteady mixed convection in a driven cavity using an externally excited sliding lid," European Journal of Mechanics B: Fluids, vol. 26, no. 5, pp. 669-687, 2007.

[37] M. M. Abdelkhalek, "Mixed convection in a square cavity by a perturbation technique," Computational Materials Science, vol. 42, no. 2, pp. 212-219, 2008.

[38] R. K. Tiwari and M. K. Das, "Heat transfer augmentation in a two-sided lid-driven differentially heated square cavity utilizing nanofluids," International Journal of Heat and Mass Transfer, vol. 50, no. 9-10, pp. 2002-2018, 2007.

[39] M. A. Waheed, "Mixed convective heat transfer in rectangular enclosures driven by a continuously moving horizontal plate," International Journal of Heat and Mass Transfer, vol. 52, no. 2122, pp. 5055-5063, 2009. 


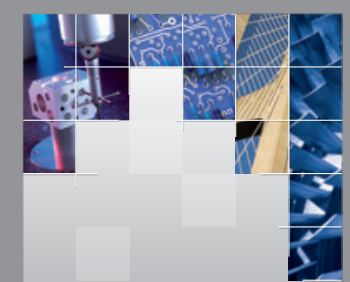

\section{Enfincering}
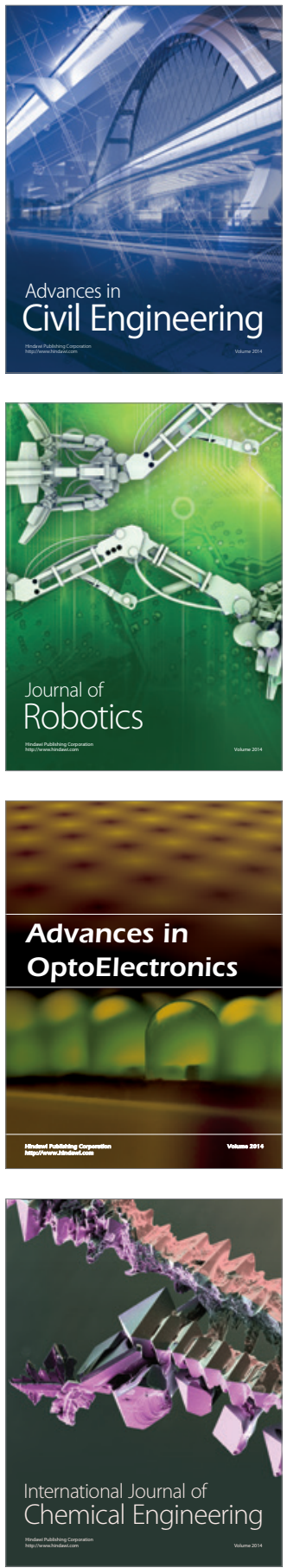

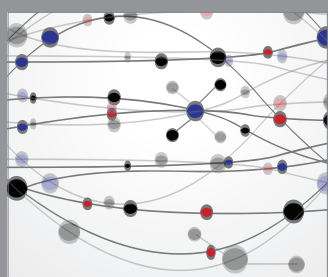

The Scientific World Journal

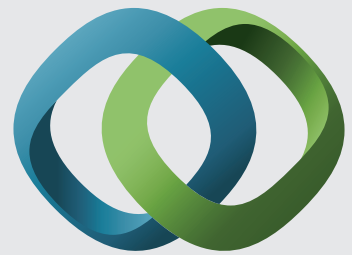

\section{Hindawi}

Submit your manuscripts at

http://www.hindawi.com
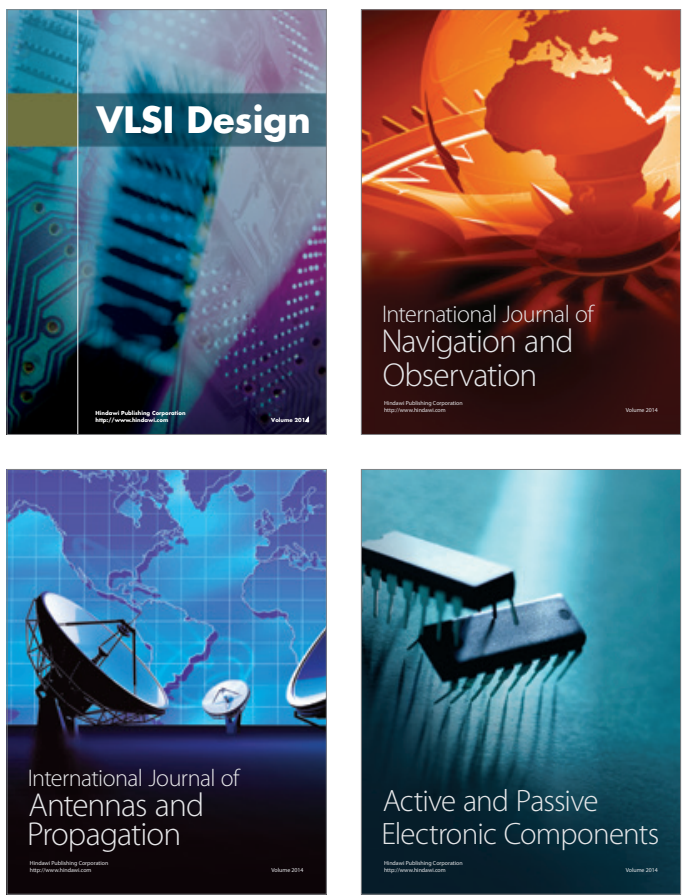
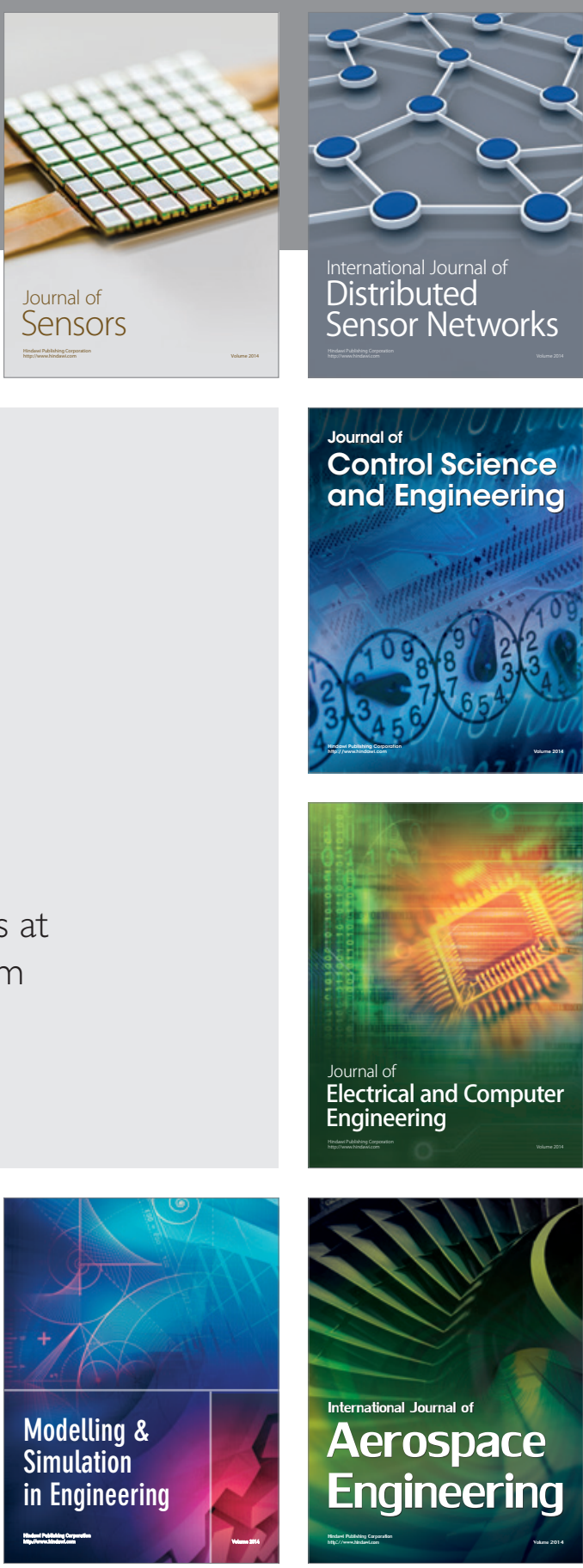

International Journal of

Distributed

Sensor Networks

Journal of

Control Science

and Engineering
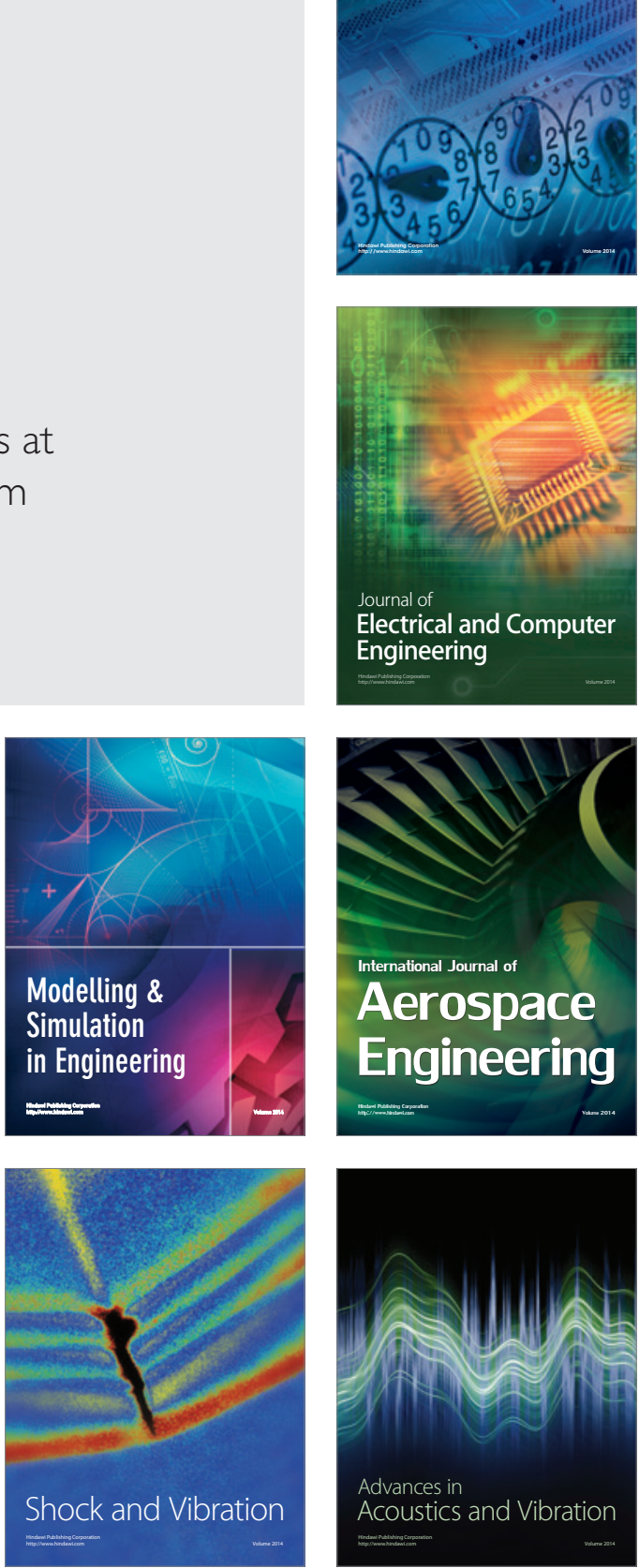